Article

\title{
Important Factors Affecting Rural Tourists' Aesthetic Experience: A Case Study of Zoumatang Village in Ningbo
}

\author{
Weiwei Zhou ${ }^{1,2}\left(\mathbb{D}\right.$, Li-Yu Chen ${ }^{3} \mathbb{D}$ and Rung-Jiun Chou ${ }^{4, *}$ \\ 1 Department of Environmental Design, College of Science and Technology, Ningbo University, \\ Ningbo 315300, China; zhouweiwei137057@gmail.com \\ 2 Ph.D. Program in Design, Chung Yuan Christian University, Taoyuan 32023, Taiwan \\ 3 Department of Interior Design, Chung Yuan Christian University, Taoyuan 32023, Taiwan; \\ liyuchen@cycu.org.tw \\ 4 Department of Landscape Architecture, Chung Yuan Christian University, Taoyuan 32023, Taiwan \\ * Correspondence: rungjiun@cycu.edu.tw
}

check for updates

Citation: Zhou, W.; Chen, L.-Y.; Chou, R.-J. Important Factors Affecting Rural Tourists' Aesthetic Experience: A Case Study of Zoumatang Village in Ningbo. Sustainability 2021, 13, 7594. https://doi.org/10.3390/ su13147594

Academic Editor: Kyle

Maurice Woosnam

Received: 8 June 2021

Accepted: 5 July 2021

Published: 7 July 2021

Publisher's Note: MDPI stays neutral with regard to jurisdictional claims in published maps and institutional affiliations.

Copyright: (C) 2021 by the authors Licensee MDPI, Basel, Switzerland. This article is an open access article distributed under the terms and conditions of the Creative Commons Attribution (CC BY) license (https:/ / creativecommons.org/licenses/by/ $4.0 /)$.

\begin{abstract}
China's countryside is rich in cultural heritage. It is an important engine for rural development and revitalization. How to improve the tourists' satisfaction with their aesthetic experience, raise the revisit rate and loyalty, and provide new methods and ideas for re-understanding the tourism experience is a topic worth discussing. This study chose Zoumatang Village in Ningbo, China, as the research target, and explored the important factors affecting tourists' satisfaction with the aesthetic experience of their visit. Through a literature review and eight experts applying the Delphi method, this paper develops a framework of important criteria for the Zoumatang Village aesthetic experience. It then ranks their importance and causal relationships using the DEMATEL-based ANP method. It also combines 16 important factors for tourist satisfaction to explore improvement measures. The research results show that pleasure is the most critical factor of the aesthetic experience offered by Zoumatang Village with interactivity, variety, associability, sociability, and stewardship as factors that need to be improved given that naturalness lies at the heart of tourists' aesthetic experience. The evaluation model of this study can provide a reference for improving the aesthetic experience of Zoumatang Village in particular, and the research methods and ideas for rural tourism development planning and integrated marketing in general. The findings can be used when investigating aesthetic experience, questionnaire making, and evaluation optimization related to tourism.
\end{abstract}

Keywords: aesthetic experience; satisfaction; Zoumatang Village; Delphi; DEMATEL; ANP

\section{Introduction}

China's countryside is rich in cultural heritage. It is a tourist place combining leisure and education and an important engine for rural development and revitalization [1]. The implementation of the new countryside policies, including beautiful countryside, characteristic towns, and rural revitalization, has ushered in new opportunities for rural revival. According to statistics from China's National Tourism Administration, there are three golden weeks each year in which $70 \%$ of urban residents choose rural tourism activities and each golden week leading to about 60 million person-visits [2]. According to the existing literature, tourists hope to break away from the isolation of cities, seek practicality, meet psychological needs, enhance self-actualization and strengthen social interaction [3], verify their own lifestyle and status [4], pursue novelty, broaden their horizons, relax, enjoy natural scenery, exercise and keep fit [5], experience local food, nostalgia [6], and look for "land plots" and "home plots" [7] through rural tourism to maximize pleasant [8] and novel experiences [9].

Aesthetic experience is a basic element of tourism $[10,11]$. The rise of research into aesthetic experience in China's tourism research began in the early 1990s [12]. Tourists 
experience aesthetic pleasure through their senses [13], thus, generating a subjective process in which individuals experience aesthetic sensory stimulation, thereby generating cognitive judgements and aesthetic-related emotions $[14,15]$. This sensory stimulation is perceived through sight, hearing, taste, smell, and touch. Whether sensory stimulation can produce aesthetic judgment and emotion depends on tourists' subjective and perceptual processing of the aesthetic quality of natural landscapes [16]. This process is based on individuals' own philosophies and experiences [9] and is influenced by aesthetic concepts, preferences, and culture [17-20]. The aesthetic experience of tourism is influenced by all the senses, including visual senses [9-11], the characteristics of the subject [20], interactivity $[9,21]$, immersiveness [22], and non-utility [23,24].

According to the latest statistics from the China National Tourism Administration, the annual number of rural tourists in China has reached 300 million, and the tourism income exceeds $\$ 40$ billion, accounting for nearly one third of the total number of trips in China. In 2019, the total number of rural tourism trips in China was 3.09 billion and the total income from rural tourism was $\$ 1.81$ billion [25]. In the second quarter of 2020, rural tourism increased by $148.8 \%$ [26] and has become an important force in China's domestic tourism and an effective means of developing the rural economy. With the rapid increase of tourists and the improvements made to meet their various demands, rural tourism is also facing the challenge of sustainable development. Kirillova et al. [9] pointed out that although tourist destinations are increasingly regarded as undifferentiated due to their typical products, "aesthetics" can become a key distinguishing factor in competitive markets that establishes a powerful point of differentiation to produce desirable customer impressions and meet tourists' need for an aesthetic experience. Decision-making affects the optimization direction and future development of rural tourism, so it is necessary to determine the priority of improvement factors in order to best-use the operating budget of relevant departments. D-ANP (DEMATEL-based ANP) does not take importance or relative weight as the only consideration when determining key factors and combines DEMATEL (Decision Making and Trial Evaluation Laboratory) and ANP (Analytic Network Process) to determine key factors together [27].

Thus, it is important to evaluate the satisfaction with the aesthetic experience of rural tourism and formulate promotion strategies. Aesthetic properties affect satisfaction with the tourism experience, destination loyalty [28], and revisit intentions, and also promote a willingness to visit neighboring destinations [29]. Aesthetic experience can greatly affect tourists' satisfaction with tourism and enhance their willingness to recommend a location to others [28]. Currently, the study of aesthetic experience focuses on philosophical discussion so that empirical research on the aesthetic experience offered by tourism is needed [30]. A small number of empirical studies mainly focus on the "sensory level" of aesthetic experience [31-33], ignoring its "spiritual level". In fact, the existing literature tends to regard aesthetic experience as a dimension of consumer experience (entertainment, education, aesthetics, and escape) [34], and research focuses on the role of aesthetic experience in the field of service marketing $[35,36]$. The remaining problems include: What are the main key factors that affect satisfaction with the rural aesthetic experience in China? What is the relationship between rural aesthetic experience factors? What is the difference between the evaluation criteria for the rural aesthetic experience and the general tourism aesthetic experience? Which innovations does this study propose for the evaluation criteria of rural aesthetic experience?

This study selected Zoumatang Village in Ningbo City in Zhejiang Province in China as the research subject. This village is listed in the first batch of "Discovering Charming Chinese Towns", the third batch of traditional Chinese villages and the seventh batch of famous Chinese historical and cultural villages. The paper intends to: (1) propose using the Delphi method to identify important evaluation criteria that affect the aesthetic experience of Zoumatang Village to improve tourist satisfaction; (2) evaluate the key factors accurately and draw a network causality diagram combining DEMATEL and ANP; (3) carry out an importance performance analysis (IPA) using a satisfaction questionnaire. 
Overall, based on the aesthetic experience of Zoumatang Village, this study aims to enhance tourists' willingness to revisit, improve their satisfaction, and contribute to the development planning and integrated marketing of rural tourism.

\section{Theoretical Background}

\subsection{Rural Tourism and Aesthetic Experience}

As a product, rural tourism combines culture and nature. The main motivation for Chinese people to engage in rural tourism is to return to nature, relax, and seek green, ecological scenery [37] to support their physiological status and social psychology arising from the different social environments in which they live. This superposition of social and psychological differences on individual physiological differences makes tourism motives very complicated [38].

The existing literature related to tourists' aesthetic experience is rarely directly related to China's rural tourism. In this study, the factors related to the aesthetic experience of rural tourism were consulted and used for reference. The scale [9] and environmental quality of the destination is important to the aesthetic experience $[28,39,40]$. Experience studies related to touch, smell, and taste all emphasize "genuine" or "novel" aesthetic experiences [28]. Poems, travel notes, legends, and other literary associations are integrated into the landscape and should receive greater attention when considering the enhancement of the aesthetic experience $[41,42]$. The Stimuli-Organization-Response (S-O-R) theory suggests that literary knowledge can stimulate the senses, thus, contributing to the production of an aesthetic experience [14]. Extracting all information (stories, knowledge, poems, folk customs, etc.) from different lifestyles and cultural fields from the landscape will contribute to visitors' emotions and expressions of satisfaction [43]. "Imagination" can enrich and strengthen the interpretation and judgment of beauty by filling in missing details and connecting to all dimensions of aesthetic objects [44]. Aesthetic experience can be divided into five stages: "perception", "explicit classification", "implicit classification", "cognitive mastering", and "evaluation". Each stage is a dynamic, interactive process ranging from shallow to deep [45]. An aesthetic experience scale with five dimensions: "harmony", "variation/contrast", "scene/viewing", "genuineness", and "art/architecture" [32] includes four predictive factors for the aesthetic judgment of the natural environment: variety, mystery, coherence, and legibility [46]. This leads to a four-domain model for aesthetic judgment: land cover types (i.e., grassland, forest types, wood, lawn); informational variables (i.e., variety, mystery, coherence, legibility); perception-based variables (i.e., openness, smoothness), and physical attributes (i.e., compatibility, naturalness, variety) [47]. Naturality [48], openness [49], vegetation [50], and variation [51] are identified as factors predicting aesthetic judgments. Vegetation, the degree of human influence and the typicality of the environment are important predictors of aesthetic judgment [52].

\subsection{Strategic Experiential Modules as a Dimension of Aesthetic Experience Evaluation}

Strategic experiential modules (SEMs) include sensory experiences (sense) related to sight, hearing, touch, taste, and smell along with emotional experiences (feelings), which reflect the customer's inner feelings and emotions, arouse customer interest and create a thinking experience of cognition and problem-solving in a creative way (thought) and an action experience (act), which interact and change people's lifestyle. These can help people relate to society and establish a personal experience of a certain brand preference (relate). The ultimate goal of the marketing module is to create an overall experience [53]. SEMs mostly include the content of tourists' aesthetic experience mentioned in this study. In recent years, some scholars have applied experiential marketing theory to research related to the tourist experience. SEMs were used to develop a scale to measure the experience of theme park tourists to fill in the research on the experience components of theme parks [54]. SEMs were used to explore the visitor experience and prove the applicability of SEMs from the perspective of management. Musa et al. [55] concluded that among these five dimensions, thinking and feeling were the most frequently expressed. 
Zoumatang Village is noted as "Siming ancient county and state of literature with beautiful scenery and abundant resources". The village was founded in 988 A.D. during the Northern Song Dynasty and is a typical blood-relationship village of the surname Chen, which has lived together for over a thousand years. It has seen 76 Jinshi (candidates in the highest imperial examinations) and is hailed as "the first village of Jinshi in China". In 2007, Ningbo City, Yinzhou District and Jiangshan Town spent huge amounts of money on renovation, leaders at all levels paid attention to support, enthusiastic people actively intervened, tapping into cultural resources, and substantial tourism began to start [56]. Driven by the protection of the ancient village and tourism, the village has developed a primary industry based on ecological and tourist agriculture, a secondary industry based on small-scale processing related to tourism, and a tertiary industry led by tourism and related services [57]. This paper focuses on the aesthetic tourism experience of Zoumatang Village using experiential marketing theory applied to five major dimensions of its tourist aesthetic experience design. Combined with other discussions in the literature and case analyses, this paper selects the corresponding preliminary tourist aesthetic experience design criteria, which include scale, genuineness, disturbance, naturalness, coherence, variety, and stewardship (sense); mysteriousness, pleasure, and distinctiveness (feel); education and associability (thought); interactivity and Tech-awareness (act); and sociability and recognizability (relate).

\subsection{DEMATEL-Based ANP to Explore Key Factors}

AHP (Analytic Hierarchy Process) is an effective method to determine key factors [58]. Saaty's subsequent ANP (Analytic Network Process) can effectively overcome the disadvantage that AHP assumes that factors at each level in the hierarchical architecture need to be independent of each other by allowing dependencies between criteria [59]. DEMATEL adopted the degree of interaction between factors to determine the causal relationship between all elements and provide a feasible scheme [60]. The DEMATEL method was used to evaluate the interaction and weight between the landscape aesthetic quality and the spatial index of the Gharasoo watershed in Golestan province in northern Iran, and to determine the correlation between the aesthetic value and the spatial index [61]. "Creativity" is the key criterion of future restaurant space design, and an evaluation model of "creativity" has been developed using DEMATEL [62]. D-ANP can improve the supermatrix operation of traditional ANP, treat different clusters as issues of equal importance and avoid the logical inconsistencies that may occur when experts fill in and answer questions. DEMATEL's "total impact matrix" is directly used as the "unweighted super matrix" of ANP, eliminating the paired comparison matrix consistency test [63]. D-ANP is convenient and practical in operation and in recent years has become widely used in fields such as tourist experience, marketing strategy, and sustainable management. Fuzzy theory, D-ANP, and the Technique for Order Preference by Similarity to Ideal Solution (TOPSIS) were used to investigate the issue of selecting scenic destinations for ecotourism [64]. An improved D-ANP-mV model, which provides suggestions for systematically improving the quality of life and livability of Xingshisi Village, China, has been put forward [65].

\section{Methods}

The qualitative research includes a literature review and using SEMs as the five major dimensions, and the quantitative research includes the Delphi method, D-ANP, and IPA. (1) The Delphi method was employed to deploy expert questionnaires and establish important criteria for Zoumatang Village aesthetic experience design; (2) DEMATELbased ANP was used to determine the importance order of factors and draw the causality diagram between them. (3) IPA was adopted to analyze the distribution of Zoumatang Village aesthetic experience criteria and the corresponding satisfaction. 


\subsection{Delphi Method}

The Delphi method, including its modified option, is a group decision-making method. Experts from different fields put forward multiple views in the first round of semi-structured questionnaires. The feedback from these questionnaires allows them to understand each other's opinions, revise their own views and, finally, reach a consensus [66]. The experts selected in this study are professionals from the rural settlement space environment planning and design team and teachers from universities with experience in rural environment art and design and rural settlement planning and design. A total of eight experts formed the expert group. Due to funding, time, and the effect of COVID-19, it was difficult to conduct the study in a more comprehensive way. In order to make the expert panel more representative, the study was conducted from both academic and industry perspectives.

Senior academic experts in the fields of landscape impact assessment, environmental behavior research, landscape and recreational resources management, social landscape construction, and space culture and design education were invited to conduct multiple rounds of in-depth interviews over the summer and winter holidays. In terms of the selection of industry experts, senior industry experts who have graduated from top art and design institutions in China and carried out practical work in space design for 30 years were chosen to provide a comprehensive analysis of the issues from both theoretical and practical perspectives and to offer more profound opinions. The background of the experts is shown in Table 1.

Table 1. Backgrounds of the Delphi respondents.

\begin{tabular}{|c|c|c|}
\hline No. & Position & Experience \\
\hline 1 & University teacher & $\begin{array}{l}\text { Thirty-five years of working experience as a university } \\
\text { teacher, Ph.D., Professor, Director of the Outdoor Recreation } \\
\text { Society, Director of the Garden Landscape Society, and } \\
\text { Executive Director of the Landscape Society. Research fields: } \\
\text { landscape design and planning, landscape impact } \\
\text { assessment, environmental behavior research, public art } \\
\text { and criticism. }\end{array}$ \\
\hline 2 & University teacher & $\begin{array}{l}\text { Fifteen years of working experience as a university teacher, } \\
\text { Ph.D., Associate Professor, research fields: health and } \\
\text { healing landscape, landscape and recreation resource } \\
\text { management, recreation area planning. }\end{array}$ \\
\hline 3 & University teacher & $\begin{array}{l}\text { Eighteen years of working experience as a university } \\
\text { teacher, Ph.D. in planning and landscape, Associate } \\
\text { Professor, research fields: landscape planning and design, } \\
\text { urban water environment management, social landscape } \\
\text { construction and development, landscape pluralistic } \\
\text { education. }\end{array}$ \\
\hline 4 & University teacher & $\begin{array}{l}\text { Thirty years of working experience as a university teacher, } \\
35 \text { years of practical work in space design, Ph.D. in design, } \\
\text { Professor, research fields: space culture, universal design, } \\
\text { design thinking, cultural creativity, design education. }\end{array}$ \\
\hline 5 & University teacher & $\begin{array}{l}\text { Fourteen years of working experience as a university } \\
\text { teacher, } 14 \text { years of practical work in space design, Ph.D. in } \\
\text { design, research fields: landscape planning and design, } \\
\text { environmental art design, design education. }\end{array}$ \\
\hline
\end{tabular}


Table 1. Cont.

\begin{tabular}{ccl}
\hline No. & Position & \multicolumn{1}{c}{ Experience } \\
\hline 6 & University teacher & $\begin{array}{l}\text { Seven years of working experience as a university teacher, } \\
\text { Ph.D. in design, research fields: landscape planning and } \\
\text { design, design education. }\end{array}$ \\
\hline 7 & Design director & $\begin{array}{l}\text { Owner of an environmental art design company, who has } \\
\text { carried out practical work in space design for 30 years and } \\
\text { has planned and designed spatial environments. }\end{array}$ \\
\hline 8 & Design director & $\begin{array}{l}\text { Owner of an environmental art design company, who has } \\
\text { carried out practical work in space design for 30 years and } \\
\text { has planned and designed spatial environments. }\end{array}$ \\
\hline
\end{tabular}

\subsection{DEMATEL-Based ANP}

According to the D-ANP operation framework [27], this study established a data analysis and scheme selection model as shown in Figure 1 to identify key factors and their causal relationships (See Figure 1 for details).

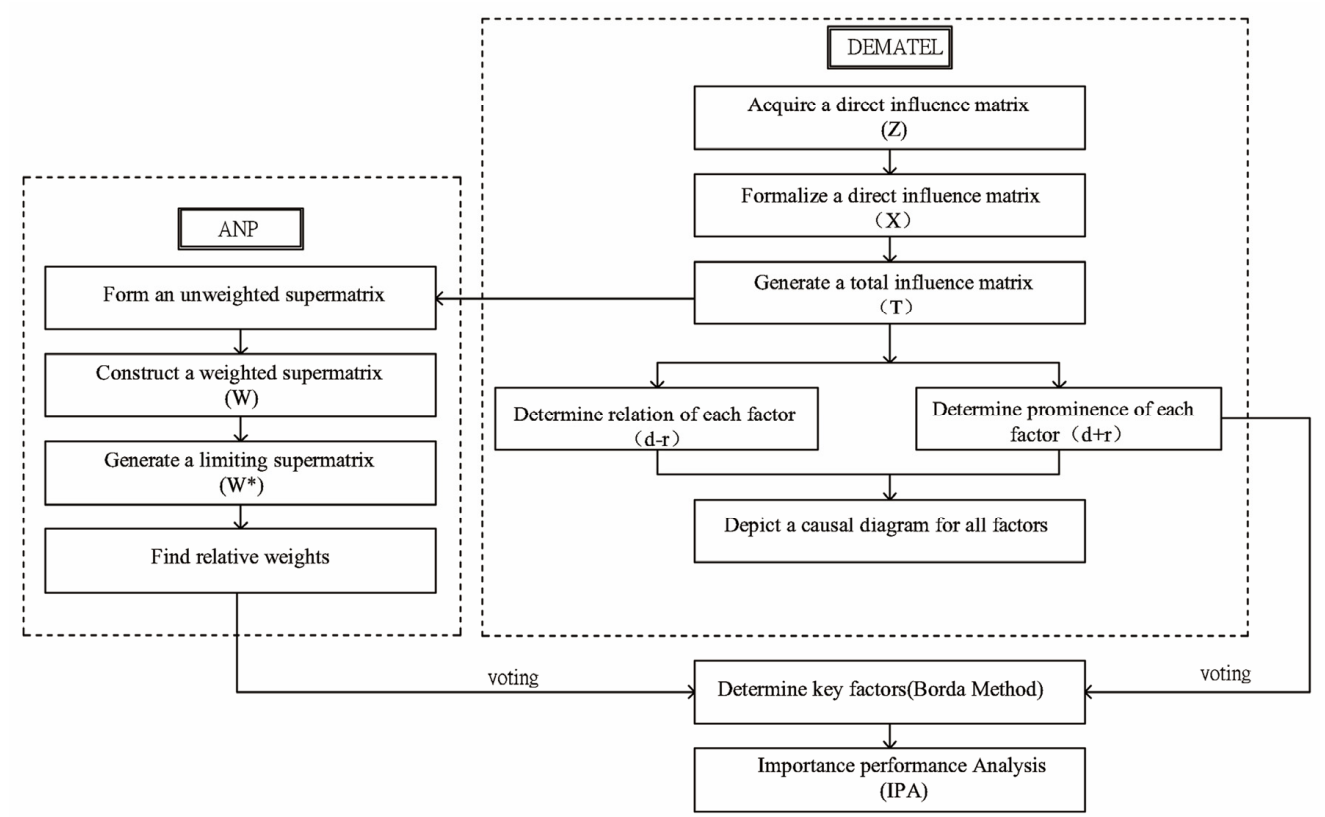

Figure 1. Data analysis and scheme selection model.

Step 1: Questionnaire design.

According to the 16 criteria of the formal research framework, a questionnaire on the degree of influence between pairwise criteria was designed with an evaluation scale ranging from 0 to 2 , see Table 2 .

Table 2. Rating scale.

\begin{tabular}{cccc}
\hline Criteria & 0 & 1 & 2 \\
\hline Association & No effect & Some effect & Strong effect \\
\hline
\end{tabular}

Step 2: Establish the direct relationship impact matrix $Z$.

By integrating the questionnaires filled in by the experts, the degree of influence between the criteria was obtained and a direct relationship influence matrix $\mathrm{Z}$ established, 
see Equation (1), where $\mathrm{n}$ represents the number of indicators, aij represents the degree to which criterion $i$ affects criterion $j$, and the value of its diagonal part is $=0$.

$$
\left[\begin{array}{cccc}
Z_{11} & Z_{12} & \cdots & Z_{1 n} \\
Z_{21} & Z_{22} & \cdots & Z_{2 n} \\
\vdots & \vdots & \vdots & \vdots \\
Z_{n 1} & \cdots & Z_{n 2} & Z_{n n}
\end{array}\right]
$$

Step 3: Establish a normalized direct relation matrix X.

Using Equations (2) and (3), the direct relation influence matrix $(Z)$ is normalized, and the normalized direct relation matrix $X$ obtained.

$$
\lambda=\frac{X=\lambda \cdot Z}{\max _{\mathrm{ij}}\left\{\max \sum_{\mathrm{i}=1}^{\mathrm{n}} \mathrm{zij}, \max \sum_{\mathrm{j}=1}^{\mathrm{n}} \mathrm{zij}\right\}}
$$

Step 4: Calculate the total impact matrix T.

The above normalization directly affects the matrix so that the total impact matrix $T$ can be calculated through $\left(T=X(I-X)^{-1}\right)$, where 0 is a zero matrix, $\mathrm{I}$ is an identity matrix, when $\lim _{k->\infty} X^{k}=0$. The formula is expressed as in Equation (4):

$$
\left(\mathrm{T}=\lim _{\mathrm{x}->\infty}\left(\mathrm{X}+\mathrm{X}^{2}+\cdots+\mathrm{X}^{\mathrm{k}}\right)=\mathrm{X}(\mathrm{I}-\mathrm{X})^{-1}\right.
$$

Step 5: Importance and relation of each criterion

The "d value" represents the degree to which one criterion directly or indirectly affects the other criteria. It can be obtained by summing up each row of the total influence matrix. The sum of each column gives the $r$ value, which indicates the degree to which the criterion is directly or indirectly affected by other criteria. $(d+r)$ can be used to find out the degree of importance; the higher the value, the higher the degree of importance of the criterion. $(d-r)$ can be used to find out the degree of correlation. If $(d-r)$ is positive, the criterion tends to actively influence other criteria and is classified as a cause; priority can be given to improving such criteria. If the value of $(\mathrm{d}-\mathrm{r})$ is negative, the criterion bias is affected and classified as an outcome.

Step 6: The total influence matrix is normalized to generate a weighting matrix $\mathrm{W}$.

Step 7: $\mathrm{W}$ is multiplied by itself until it converges and the limit super matrix $\mathrm{W}^{*}$ is generated and the weight of each criterion obtained.

Step 8: Determine the importance order of the criteria.

Using the Borda score, the final importance ranking of each criterion is obtained by summing the DEMATEL ranking + the D-ANP ranking, which gives the key criteria.

\subsection{IPA}

IPA is a technology to measure the importance and performance of attributes, which can effectively solve the priority allocation of resources [60]. Cheng et al. [67] proposed the application of IPA and a fuzzy logic method was proposed to determine the influence range of various attributes on visitor satisfaction. IPA generates four quadrants with "importance" as the vertical axis and "performance value" as the horizontal axis. The quadrant with high importance and low performance value represents Concentrate Here, and the quadrant with high importance and high performance value represents Keep Up the Good Work. The quadrant with low importance and low performance value represents Low Priority and the quadrant with low importance and high performance value may indicate Possible Overkill. 


\section{Results}

\subsection{Establish a Criteria Evaluation Framework}

In this study, two rounds of the Delphi method were conducted. In the first round, experts scored the preliminary criteria evaluation framework based on experience, intuition, and value judgment. They them put forward various viewpoints and suggestions for revision. In the second round, experts reached a consensus on the revised criteria, and finally determined a formal research framework including five dimensions and 16 criteria. They then produced a formal criteria evaluation framework, see Table 3.

Table 3. Descriptions of the revised assessment criteria.

\begin{tabular}{|c|c|c|c|}
\hline Dimension & & Criteria & Description \\
\hline \multirow{7}{*}{ Sense (A) } & A1 & Scale & $\begin{array}{c}\text { The scale of environment and the degree of open } \\
\text { vision, the density of landscape elements, and the } \\
\text { number of obstacles. }\end{array}$ \\
\hline & $\mathrm{A} 2$ & Genuineness & $\begin{array}{l}\text { Through perception, one can experience the real } \\
\text { environment such as local food, sound, water, air, } \\
\text { human history, etc. }\end{array}$ \\
\hline & A3 & Naturalness & $\begin{array}{c}\text { Level of Wilderness, natural index and ecological } \\
\text { degree of tourist spots. }\end{array}$ \\
\hline & $\mathrm{A} 4$ & Disturbance & $\begin{array}{l}\text { Natural disturbance (fire and debris flow), building } \\
\text { disturbance (infrastructure, temporary buildings), } \\
\text { foreign culture and foreign personnel disturbance. }\end{array}$ \\
\hline & A5 & Coherence & $\begin{array}{c}\text { The design of settlement space environment has } \\
\text { self-evident integrity. }\end{array}$ \\
\hline & A6 & Variety & $\begin{array}{l}\text { Architectural and artistic elements are organically } \\
\text { integrated within the vegetation of the terrain. The } \\
\text { scale of landscape elements and landscape units is } \\
\text { fine and varied. }\end{array}$ \\
\hline & A7 & Stewardship & $\begin{array}{c}\text { Shows a sense of order through active and } \\
\text { careful management. }\end{array}$ \\
\hline \multirow{3}{*}{ Feel (B) } & B1 & Mysteriousness & $\begin{array}{l}\text { Cannot be perceived fully, stimulates people's } \\
\text { desire for knowledge and exploration. }\end{array}$ \\
\hline & B2 & Pleasure & $\begin{array}{l}\text { Create the aesthetic pleasure of comedy/tragedy } \\
\text { and popular/elegant aesthetic pleasure. }\end{array}$ \\
\hline & B3 & Distinctiveness & $\begin{array}{l}\text { It has landscape recognition and can form a } \\
\text { powerful, unforgettable, visual image. }\end{array}$ \\
\hline \multirow{2}{*}{ Think (C) } & $\mathrm{C} 1$ & Education & $\begin{array}{l}\text { Meet the needs of tourists to contact nature, know } \\
\text { nature and know human history. }\end{array}$ \\
\hline & $\mathrm{C} 2$ & Associability & $\begin{array}{l}\text { Improve tourists' interpretation of nature through } \\
\text { appropriate literary renderings. }\end{array}$ \\
\hline \multirow[b]{2}{*}{ Act (D) } & D1 & Interactivity & $\begin{array}{l}\text { Promote the positive interaction between people } \\
\text { and the environment, and maintain the continuous, } \\
\text { holistic, and perceptual unity of the environment. }\end{array}$ \\
\hline & D2 & Tech-awareness & $\begin{array}{c}\text { Data recording, sharing and evaluation, route } \\
\text { guidance, target planning, online and offline } \\
\text { shopping needs, value-added information } \\
\text { (local events). }\end{array}$ \\
\hline \multirow[b]{2}{*}{ Relate (E) } & E1 & Sociability & $\begin{array}{l}\text { Promote family or friend relationships and meet } \\
\text { the needs for making friends. }\end{array}$ \\
\hline & E2 & Recognizability & $\begin{array}{c}\text { Show the location, pattern, form, and content of the } \\
\text { region, and arouse the resonance and support } \\
\text { of tourists. }\end{array}$ \\
\hline
\end{tabular}

In this study, the maximum average split proposed by Teng (2014) [59] was used for adjustment, and the consensus difference index, CDI, was calculated to test the degree of consensus of expert groups. The threshold value of the consensus difference determined in this study is $\mathrm{CDI} \leq 0.1$. In the first round of questionnaires, experts gave preliminary 
scores for each criterion and put forward suggestions for modifying, adding, and deleting the criterion. In the first round of the questionnaire survey, the criteria with CDI value $>0.1$ included "naturalness" and "distance", which means that experts failed to reach a consensus. The second round of questionnaires was completed on the basis of the adjustment to the first round of questionnaires. Experts reached a consensus on the 16 important criteria finally refined and screened out, and the CDI values of the 16 evaluation criteria were all $\leq 0.1$. Despite the score for the "education" criterion in this study not being high, it is also included in the final formal research framework since this criterion is a unique experience module for Zoumatang Village as the first Jinshi Village in China.

\subsection{Identify Key Elements of the Criteria}

In the total influence matrix $\mathrm{T}$ (see Tables 4 and 5), each column is summed to obtain a column sum (d), and each row is summed to obtain a row sum (r). Then the importance $(\mathrm{d}+\mathrm{r})$ value and the correlation $(\mathrm{d}-\mathrm{r})$ value are calculated.

Table 4. Total influence matrix $\mathrm{T}$ (dimensions).

\begin{tabular}{ccccccc}
\hline $\mathbf{T}$ & $\mathbf{A}$ & $\mathbf{B}$ & $\mathbf{C}$ & $\mathbf{D}$ & $\mathbf{E}$ & $\mathbf{d}$ \\
\hline $\mathbf{A}$ & 0.740 & 1.193 & 0.986 & 0.957 & 1.073 & 4.949 \\
\hline $\mathbf{B}$ & 0.789 & 0.797 & 0.852 & 0.853 & 0.929 & 4.220 \\
\hline $\mathbf{C}$ & 0.807 & 0.959 & 0.683 & 0.871 & 0.917 & 4.237 \\
\hline $\mathbf{D}$ & 0.732 & 0.851 & 0.745 & 0.602 & 0.800 & 3.730 \\
\hline $\mathbf{E}$ & 0.620 & 0.857 & 0.705 & 0.692 & 0.614 & 3.487 \\
\hline $\mathbf{r}$ & 3.688 & 4.657 & 3.971 & 3.975 & 4.333 & 3.688 \\
\hline
\end{tabular}

Table 5. Total influence matrix $\mathrm{T}$ (criterion).

\begin{tabular}{|c|c|c|c|c|c|c|c|c|c|c|c|c|c|c|c|c|c|}
\hline $\mathbf{T}$ & 1 & 2 & 3 & 4 & 5 & 6 & 7 & B1 & 32 & 3 & $\mathrm{C} 1$ & 2 & D1 & 22 & E1 & E2 & d \\
\hline $\mathrm{A}$ & 0.121 & 0 & 01 & 47 & 66 & 225 & 2 & 5 & 3 & 3 & 5 & 20 & 217 & 130 & 0.216 & .215 & 3.097 \\
\hline $\mathrm{A} 2$ & 0.187 & 0 & 224 & 52 & 0 & 0.247 & 0 & 0 & 5 & 189 & & & & & 224 & 260 & 228 \\
\hline A3 & +0 & 0.256 & 170 & 0.194 & 207 & 0.294 & 0.222 & 0.203 & 0.322 & 0.240 & 0.236 & 0.286 & 0.201 & 0.147 & 0.267 & 0.293 & 3.895 \\
\hline A & 16 & 202 & 0.225 & 104 & 1 & 21 & 0.223 & 0.188 & 30 & 177 & 68 & 221 & .236 & 0.137 & 0.247 & 0.246 & 3.140 \\
\hline A5 & 0138 & 149 & 170 & 129 & 101 & 0192 & 0213 & 0166 & 0212 & .174 & 0.148 & 0.186 & 0.190 & 34 & .195 & 0.209 & 2.708 \\
\hline A6 & 0.181 & 0.200 & 0.225 & 0.156 & 0.171 & 0.177 & 0.235 & 0.216 & 0.265 & 0.200 & 0.205 & 0.251 & 0.234 & 0.164 & 0.261 & 0.254 & 3.393 \\
\hline A7 & 0.100 & 0.168 & 0.131 & 0.147 & 0.102 & 0.202 & 0.147 & 0.104 & 0.223 & 0.150 & 0.100 & 0.175 & 0.212 & 0.102 & 0.228 & 0.247 & 2.900 \\
\hline B1 & 0.153 & 169 & 0.178 & 4 & 7 & 0.191 & 3 & 7 & 0 & 3 & 0134 & 2 & 198 & 8 & 1 & 0.194 & 2.637 \\
\hline B2 & 0.159 & 0.167 & 0.193 & 0.127 & 0.155 & 0.251 & 0.205 & 0.188 & 0.189 & 0.183 & 0.170 & 0.239 & 0.265 & 0.164 & 0.266 & 0.252 & 3.172 \\
\hline B3 & 0.156 & 0.145 & 0.177 & 0.107 & 0.163 & 0.190 & 0.161 & 0.181 & 0.233 & 0.122 & 0.166 & 0.212 & 0.199 & 0.136 & 0.203 & 0.211 & 2.762 \\
\hline $\mathrm{C} 1$ & 0.127 & 0.143 & 0.160 & 0.103 & 0114 & 0.176 & 0.183 & 0.147 & 0.208 & 0.155 & 0.117 & 0.210 & 0.210 & 0.161 & 0.214 & 0.217 & 2.643 \\
\hline $\mathrm{C} 2$ & 0.132 & 147 & 0163 & 0.099 & 133 & 0.176 & 0.168 & 0.199 & 0.235 & 0.180 & 0.158 & 0.148 & 0.208 & 0.151 & 0.207 & 0.209 & 2.714 \\
\hline D1 & 0.133 & 0.151 & 0.191 & 0.140 & 0.124 & 0.186 & 0.209 & 0.170 & 0.226 & 0.156 & 0.192 & 0.220 & 0.166 & 0.177 & 0.258 & 0.245 & 2.943 \\
\hline D2 & 0.113 & 0.128 & 0.135 & 0.105 & 0.110 & 0.170 & 0.184 & 0.167 & 0.208 & 0.155 & 0.168 & 0.189 & 0.216 & 0.097 & 0.205 & 0.206 & 2.556 \\
\hline E1 & 0.106 & 0.116 & 0.168 & 0.096 & 0.103 & 0.151 & 4 & 0. & 0. & 0. & 51 & 73 & 0.221 & 5 & 0. & 0.190 & 2.50 \\
\hline E2 & 0.109 & 0.130 & 0.165 & 0.101 & 8 & 0.164 & 0.1 & 0.145 & 0.1 & 0.1 & 0.144 & 0.168 & 0.162 & 0.106 & 0.192 & 0.140 & 2.374 \\
\hline $\mathbf{R}$ & 2.346 & 2.612 & 2.955 & 2.010 & 2.266 & 3.208 & 3.057 & 2.892 & 3.678 & 2.700 & 2.697 & 3.336 & 3.418 & 2.241 & 3.513 & 3.587 & \\
\hline
\end{tabular}


As shown in Tables 6 and 7 , the $(\mathrm{d}+\mathrm{r})$ value of "emotional experience" and "pleasure" criteria are the largest, which is the central influencing factor; the "sensory experience" dimension and the "naturalness" criterion have the largest $(\mathrm{d}-\mathrm{r})$ values, which are important leading factors; while the $(\mathrm{d}-\mathrm{r})$ values of the "relevance experience" dimension and the "recognizability" criteria are the smallest, and are most influenced by other criteria that belong to the result factors.

Table 6. Prominence and relation of each dimension.

\begin{tabular}{ccccccc}
\hline No. & Dimension & $\mathbf{d}$ & $\mathbf{r}$ & $\mathbf{d}+\mathbf{r}$ & $\mathbf{d}+\mathbf{r}$ Ranking & $\mathbf{d}-\mathbf{r}$ \\
\hline A & Sense & 4.949 & 3.688 & 8.637 & 2 & 1.261 \\
B & Feel & 4.220 & 4.657 & 8.878 & 1 & -0.437 \\
C & Think & 4.237 & 3.971 & 8.208 & 3 & 0.266 \\
D & Act & 3.730 & 3.975 & 7.705 & 5 & -0.244 \\
E & Relate & 3.487 & 4.333 & 7.821 & 4 & -0.846 \\
\hline
\end{tabular}

Table 7. Prominence and relation of each criterion.

\begin{tabular}{ccccccc}
\hline No. & Criteria & $\mathbf{d}$ & $\mathbf{r}$ & $\mathbf{d}+\mathbf{r}$ & $\mathbf{d}+\mathbf{r}$ Ranking & $\mathbf{d}-\mathbf{r}$ \\
\hline A1 & Scale & 3.097 & 2.346 & 5.443 & 12 & 0.751 \\
\hline A2 & Genuineness & 3.228 & 2.612 & 5.841 & 9 & 0.616 \\
\hline A3 & Naturalness & 3.895 & 2.955 & 6.850 & 2 & 0.940 \\
\hline A4 & Disturbance & 3.140 & 2.010 & 5.150 & 14 & 1.131 \\
\hline A5 & Coherence & 2.708 & 2.266 & 4.974 & 15 & 0.442 \\
\hline A6 & Variety & 3.393 & 3.208 & 6.601 & 3 & 0.186 \\
\hline A7 & Stewardship & 2.900 & 3.057 & 5.957 & 7 & -0.158 \\
\hline B1 & Mysteriousness & 2.637 & 2.892 & 5.529 & 10 & -0.255 \\
\hline B2 & Pleasure & 3.172 & 3.678 & 6.850 & 1 & -0.505 \\
\hline B3 & Distinctiveness & 2.762 & 2.700 & 5.461 & 11 & 0.062 \\
\hline C1 & Education & 2.643 & 2.697 & 5.340 & 13 & -0.054 \\
\hline C2 & Associability & 2.714 & 3.336 & 6.050 & 5 & -0.623 \\
\hline D1 & Interactivity & 2.943 & 3.418 & 6.361 & 4 & -0.475 \\
\hline D2 & Tech-awareness & 2.556 & 2.241 & 4.797 & 16 & 0.315 \\
\hline E1 & Sociability & 2.352 & 3.513 & 5.865 & 8 & -1.160 \\
\hline E2 & Recognizability & 2.374 & 3.587 & 5.962 & 6 & -1.213 \\
\hline & & & & &
\end{tabular}

Summing the DEMATEL and D-ANP rankings of each criterion provides the overall ranking of the criteria as shown in Tables 8 and 9. The smaller the total score of sorting, the more important it is to represent the extent of its influence. Based on the first half of the ranking, the selected key criteria include: pleasure (B2), interactivity (D1), recognizability (E2), variation (A6), naturalness (A3), and associability (C2), Sociability (E1), and Stewardship (A7) In total, eight key criteria are those affecting rural tourists' aesthetic experience satisfaction. Among the key criteria, the emotional experience dimension accounts for one, the action experience dimension accounts for two, the related experience dimension accounts for one, and the sensory experience dimension accounts for two, this means that the sensory experience dimension needs more attention than the thinking experience dimension. 
Table 8. Ranking and integration of dimension weights.

\begin{tabular}{cccccc}
\hline No. & Dimension & D-ANP & DEMATEL & $\begin{array}{c}\text { Ranking and } \\
\text { Borda Score }\end{array}$ & $\begin{array}{c}\text { Overall } \\
\text { Ranking }\end{array}$ \\
\hline A & Sense & 5 & 2 & 7 & 4 \\
\hline B & Feel & 1 & 1 & 2 & 1 \\
\hline C & Think & 3 & 3 & 6 & 2 \\
\hline D & Act & 4 & 5 & 9 & 5 \\
\hline E & Relate & 2 & 4 & 6 & 2 \\
\hline
\end{tabular}

Table 9. Ranking and integration of criteria weights.

\begin{tabular}{cccccc}
\hline No. & Criteria & D-ANP & DEMATEL & $\begin{array}{c}\text { Ranking and } \\
\text { Borda Score }\end{array}$ & $\begin{array}{c}\text { Overall } \\
\text { Ranking }\end{array}$ \\
\hline A1 & Scale & 13 & 12 & 25 & 13 \\
\hline A2 & Genuineness & 12 & 9 & 21 & 10 \\
\hline A3 & Naturalness & 8 & 2 & 10 & $5 \star$ \\
\hline A4 & Disturbance & 16 & 14 & 30 & 14 \\
\hline A5 & Coherence & 15 & 15 & 30 & 14 \\
\hline A6 & Variety & 6 & 3 & 9 & $4 \star$ \\
\hline A7 & Stewardship & 7 & 7 & 14 & $8 \star$ \\
\hline B1 & Mysteriousness & 9 & 10 & 19 & 9 \\
\hline B2 & Pleasure & 1 & 1 & 22 & 11 \\
\hline B3 & Distinctiveness & 11 & 11 & 23 & 12 \\
\hline C1 & Education & 10 & 13 & 10 & $5 \star$ \\
\hline C2 & Associability & 5 & 5 & 8 & $2 \star$ \\
\hline D1 & Interactivity & 4 & 4 & 30 & 14 \\
\hline D2 & Tech-awareness & 14 & 16 & 11 & $7 \star$ \\
\hline E1 & Sociability & 3 & 8 & 8 & $2 \star$ \\
\hline E2 & Recognizability & 2 & 6 & & 9 \\
\hline Th & & & 6 & 2 & \\
\hline
\end{tabular}

The sign $\star$ in Table 9 means key criteria.

\subsection{Draw a Relationship and Causality Diagram between the Criteria}

Chose the most important "pleasure" criterion as the core of the criterion relationship diagram. As can be seen from Figure 2, "Disturbance" and "Naturality" affect "Pleasure". "Pleasure" affects "Recognizability" and "Sociability". Complete arrows are used to represent the influence of key criteria, and dashed arrows are used to represent the influence of non-key criteria. Interactivity (D1), recognizability (E2), variation (A6), naturalness (A3), association (C2), society (E1), and stewardship (A7) are the key criteria affecting "pleasure".

Combined with Tables 7 and 9; the higher the value of $(\mathrm{d}-\mathrm{r})$, the better the effect. Therefore, the "naturalness" criterion is considered as the source criterion. In order to find out the important influence relationships between the key criteria, a simplified causality diagram of the key criteria (Figure 3) can be drawn according to the total influence matrix $\mathrm{T}$ (Table 10). 


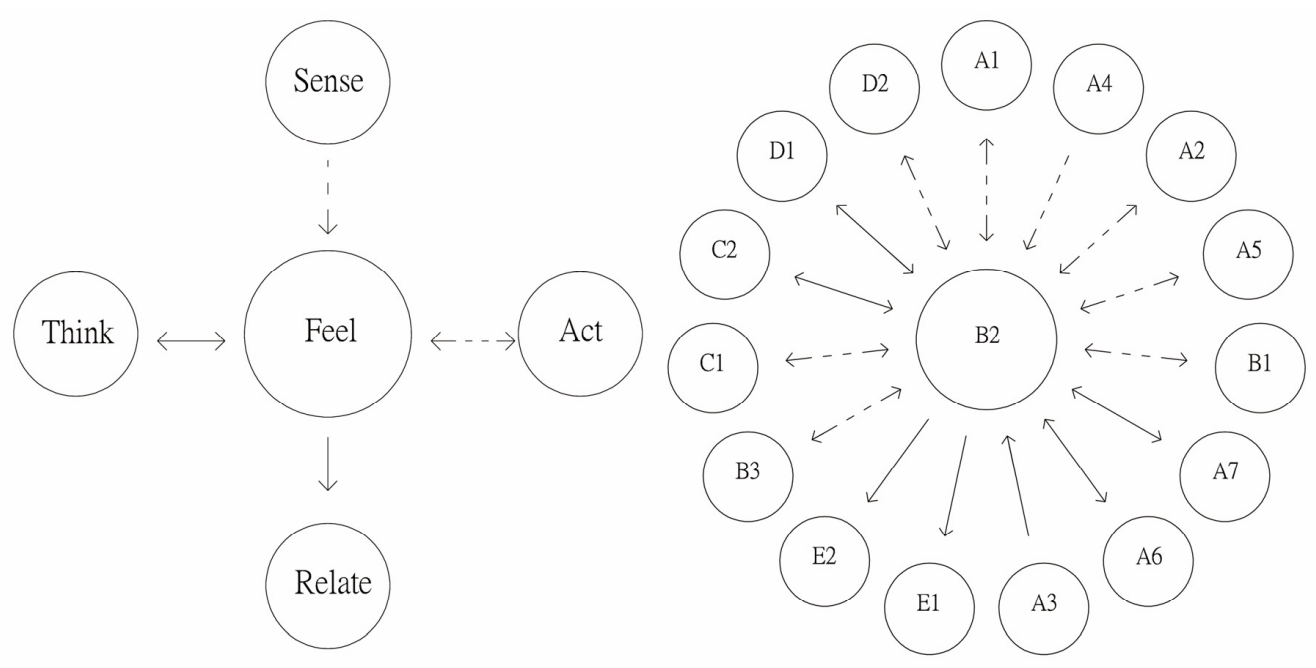

Figure 2. Dimension relationship (left), and criteria relationship (right).

Table 10. The total impact matrix $\mathrm{T}$ determines the key criteria.

\begin{tabular}{|c|c|c|c|c|c|c|c|c|c|c|c|c|c|c|c|c|c|}
\hline & & & & $\downarrow$ & & & $\downarrow$ & & & $\downarrow$ & & & $\downarrow$ & $\downarrow$ & & & $\downarrow$ \\
\hline & $\mathrm{T}$ & A1 & A2 & A3 & A4 & A5 & A6 & A7 & B1 & B2 & B3 & $\mathrm{C} 1$ & $\mathrm{C} 2$ & D1 & D2 & E1 & E2 \\
\hline & A1 & 0.121 & 0.200 & 0.201 & 0.147 & 0.166 & 0.225 & 0.192 & 0.225 & 0.253 & 0.193 & 0.175 & 0.220 & 0.217 & 0.130 & 0.216 & 0.215 \\
\hline & A2 & 0.187 & 140 & 0.224 & 152 & 0.160 & 0.247 & 0.200 & 0.220 & 0.245 & 0.189 & 0.198 & 0.227 & 0.223 & 0.134 & 0.224 & 0.260 \\
\hline \multirow[t]{3}{*}{$->$} & A3 & 0.218 & 0.256 & 0.190 & 0.194 & 0.207 & 0.294 & 0.222 & 0.263 & 0.322 & 0.240 & 0.236 & 0.286 & 0.261 & 0.147 & 0.267 & 0.293 \\
\hline & A4 & 0.161 & 0.202 & 0.225 & 0.104 & 0.151 & 0.216 & 0.223 & 0.188 & 0.239 & 0.177 & 0.168 & 0.221 & 0.236 & 0.137 & 0.247 & 0.246 \\
\hline & A5 & 0.138 & 0.149 & 0.170 & 0.129 & 0.101 & 0.192 & 0.213 & 0.166 & 0.212 & 0.174 & 0.148 & 0.186 & 0.190 & 0.134 & 0.195 & 0.209 \\
\hline \multirow[t]{3}{*}{$->$} & A6 & 0.181 & 0.200 & 0.225 & 0.156 & 0.171 & 0.177 & 0.235 & 0.216 & 0.265 & 0.200 & 0.205 & 0.251 & 0.234 & 0.164 & 0.261 & 0.254 \\
\hline & A7 & 0.155 & 0.168 & 0.191 & 0.147 & 0.162 & 0.202 & 0.147 & 0.164 & 0.223 & 0.150 & 0.168 & 0.175 & 0.212 & 0.162 & 0.228 & 0.247 \\
\hline & B1 & 0.153 & 0.169 & 0.178 & 0.104 & 0.127 & 0.191 & 0.153 & 0.127 & 0.237 & 0.163 & 0.134 & 0.212 & 0.198 & 0.108 & 0.191 & 0.194 \\
\hline \multirow[t]{8}{*}{7} & B2 & 0.159 & 0.167 & 0.193 & 0.127 & 0.155 & 0.251 & 0.205 & 0.188 & 0.189 & 0.183 & 0.170 & 0.239 & 0.265 & 0.164 & 0.266 & 0.252 \\
\hline & B3 & 0.156 & 0.145 & 0.177 & 0.107 & 0.163 & 0.190 & 0.161 & 0.181 & 0.233 & 0.122 & 0.166 & 0.212 & 0.199 & 0.136 & 0.203 & 0.211 \\
\hline & $\mathrm{C} 1$ & 0.127 & 0.143 & 0.160 & 0.103 & 0.114 & 0.176 & 0.183 & 0.147 & 0.208 & 0.155 & 0.117 & 0.210 & 0.210 & 0.161 & 0.214 & 0.217 \\
\hline & $\mathrm{C} 2$ & 0.132 & 0.147 & 0.163 & 0.099 & 0.133 & 0.176 & 0.168 & 0.199 & 0.235 & 0.180 & 0.158 & 0.148 & 0.208 & 0.151 & 0.207 & 0.209 \\
\hline & D1 & 0.133 & 0.151 & 0.191 & 0.140 & 0.124 & 0.186 & 0.209 & 0.170 & 0.226 & 0.156 & 0.192 & 0.220 & 0.166 & 0.177 & 0.258 & 0.245 \\
\hline & D2 & 0.113 & 0.128 & 0.135 & 0.105 & 0.110 & 0.170 & 0.184 & 0.167 & 0.208 & 0.155 & 0.168 & 0.189 & 0.216 & 0.097 & 0.205 & 0.206 \\
\hline & E1 & 0.106 & 0.116 & 0.168 & 0.096 & 0.103 & 0.151 & 0.174 & 0.127 & 0.191 & 0.114 & 0.151 & 0.173 & 0.221 & 0.135 & 0.138 & 0.190 \\
\hline & E2 & 0.109 & 0.130 & 0.165 & 0.101 & 0.118 & 0.164 & 0.190 & 0.145 & 0.193 & 0.148 & 0.144 & 0.168 & 0.162 & 0.106 & 0.192 & 0.140 \\
\hline
\end{tabular}

The arrows in Table 10 point to the top-ranked key criteria in order to identify the most influential among the key criteria, find out the important influence relationships between the key criteria.

Figure 3 shows the interaction between key criteria: naturalness (A3) and variation (A6). Naturality (A3) directly affects other key factors. From the point of view of source management, variety (A6) directly affects pleasure (B2) and Stewardship (A7). In order to effectively improve the performance of all key factors, we can consider starting with naturalness and variety. 


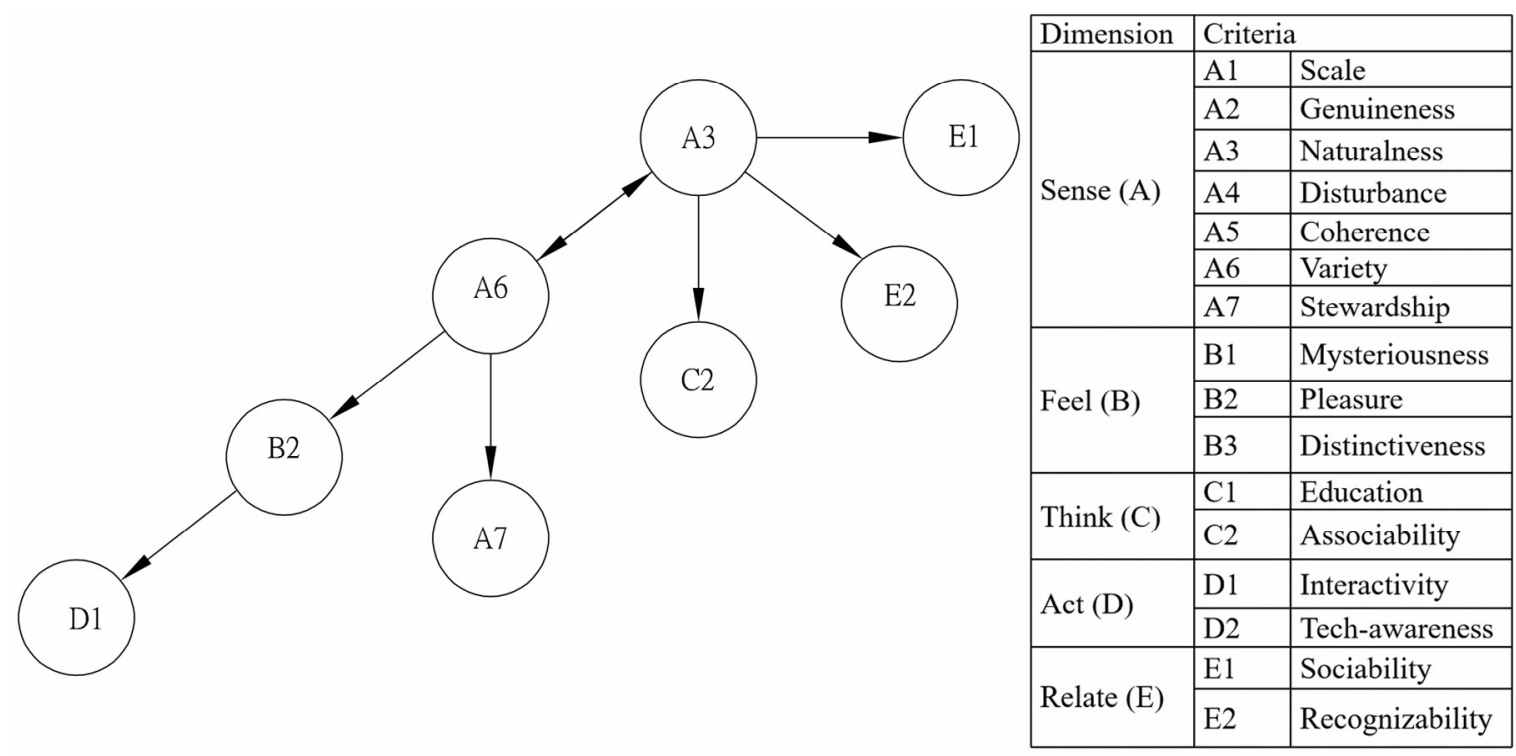

Figure 3. Causality diagram of the key criteria.

\subsection{IPA Results}

In order to present the performance of 16 criteria, this study took experts and ordinary tourists as questionnaire survey subjects. In light of the "tourists' satisfaction with aesthetic experience" criteria for Zoumatang Village, and using a 5-point Likert scale, the results were averaged, and the performance values for the 16 criteria of tourists' aesthetic experience of Zoumatang Village were obtained (See Table 11 for details).

Table 11. Zoumatang Village performance values for 16 criteria of visitors' aesthetic experience.

\begin{tabular}{|c|c|c|c|c|c|c|c|c|c|c|c|c|}
\hline Dimension & & Criteria & (1) & (2) & (3) & (4) & (5) & (6) & (7) & (8) & $\begin{array}{l}\text { Criteria Total } \\
\text { Average }\end{array}$ & $\begin{array}{c}\text { Dimension } \\
\text { Total Average }\end{array}$ \\
\hline \multirow{7}{*}{ Sense } & A1 & Scale & 4 & 4 & 4 & 3 & 4 & 4 & 4 & 3 & 3.75 & \multirow{7}{*}{3.589} \\
\hline & $\mathrm{A} 2$ & Genuineness & 4 & 4 & 4 & 5 & 4 & 4 & 4 & 4 & 4.125 & \\
\hline & A3 & Naturalness & 4 & 4 & 5 & 4 & 4 & 4 & 4 & 4 & 4.125 & \\
\hline & A4 & Disturbance & 3 & 4 & 3 & 4 & 3 & 4 & 3 & 2 & 3.25 & \\
\hline & A5 & Coherence & 3 & 4 & 5 & 3 & 3 & 3 & 3 & 3 & 3.375 & \\
\hline & A6 & Variety & 4 & 4 & 3 & 3 & 2 & 3 & 3 & 3 & 3.125 & \\
\hline & A7 & Stewardship & 4 & 4 & 5 & 3 & 3 & 2 & 3 & 3 & 3.375 & \\
\hline \multirow{3}{*}{ Feel } & $\mathrm{B} 1$ & Mysteriousness & 4 & 4 & 3 & 4 & 3 & 4 & 4 & 4 & 3.75 & \multirow{3}{*}{3.75} \\
\hline & B2 & Pleasure & 4 & 4 & 4 & 4 & 3 & 4 & 4 & 3 & 3.75 & \\
\hline & B3 & Distinctiveness & 3 & 4 & 4 & 4 & 5 & 4 & 4 & 2 & 3.75 & \\
\hline \multirow[b]{2}{*}{ Think } & $\mathrm{C} 1$ & Education & 4 & 3 & 3 & 5 & 5 & 3 & 4 & 3 & 3.75 & \multirow{2}{*}{3.375} \\
\hline & $\mathrm{C} 2$ & Associability & 4 & 4 & 3 & 3 & 2 & 3 & 3 & 2 & 3 & \\
\hline \multirow[b]{2}{*}{ Act } & D1 & Interactivity & 3 & 4 & 3 & 3 & 3 & 3 & 3 & 2 & 3 & \multirow[b]{2}{*}{2.75} \\
\hline & D2 & Tech-awareness & 3 & 3 & 2 & 3 & 2 & 2 & 3 & 2 & 2.5 & \\
\hline \multirow{2}{*}{ Relate } & E1 & Sociability & 4 & 4 & 3 & 4 & 4 & 2 & 3 & 2 & 3.25 & \multirow{2}{*}{3.563} \\
\hline & E2 & Recognizability & 4 & 4 & 4 & 4 & 4 & 3 & 4 & 4 & 3.875 & \\
\hline
\end{tabular}

The main purpose of IPA is to examine indicators that need to be improved, maintained continuously, paid too much attention, or do not need to be paid attention to in terms of the performance value and relative importance of the criteria. In the satisfaction questionnaire of this study, some criteria have multiple related questions in order to analyze the specific situation more deeply. The satisfaction of each criterion in Table 11 refers to the overall average score for that criterion. After discussion with the interviewees, it was agreed that the total average score for each criterion plus the total average score of 3.5 points should be taken as the critical value for whether the performance is satisfactory or not. This study constructed an analysis matrix of importance and performance value 
with two dimensions of importance and performance value, in which the importance is ranked by the Borda score; the lower the score, the higher the importance. The performance value was calculated according to the results of the interviewees' questionnaire (scoring the performance of each item with 0-5). As shown in Figure 4, a performance value of above 3.5 points for a criterion represents good performance (i.e., scale, genuineness, naturalness, mysteriousness, pleasure, distinctiveness, education, recognizability), which should be maintained continuously, and a criterion scoring below 3.5 points needs to be improved. The average performance for the emotional experience and action experience dimensions shown by Table 11 are 3.75 and 2.75, respectively, so the emotional experience dimension is better than the action experience dimension.

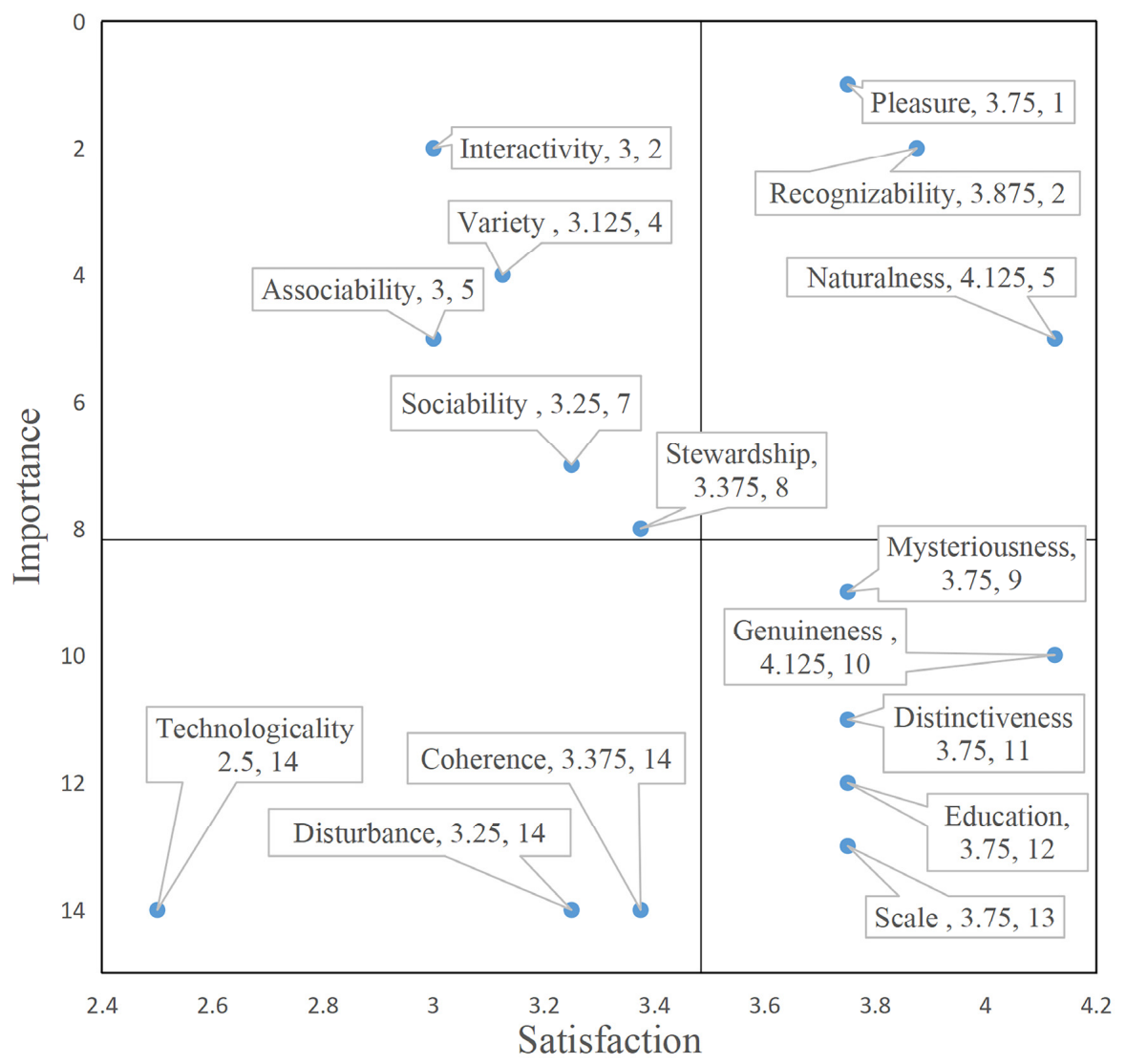

Figure 4. IPA (Importance-Performance Analysis) of visitors' aesthetic experience in Zoumatang Village.

\section{Discussion}

\subsection{Factor Analysis}

Using the Delphi method allows 16 important criteria to be selected, namely, pleasure, interactivity, recognizability, variety, naturalness, associability, sociability, stewardship, mysteriousness, genuineness, distinctiveness, education, scale, disturbance, coherence, and tech-awareness. On this basis, the DEMATEL-based ANP and IPA analyses allow the performance values and key factors of each criterion to be further obtained. In order to comprehensively analyze the factors influencing the satisfaction of tourists with their aesthetic experience in Zoumatang Village, it is necessary to discuss 16 criteria as follows:

\subsubsection{Key Factors and High Satisfaction}

"Pleasure" is a key criterion for visitors' aesthetic experience at Zoumatang Village, ranking first. Its satisfaction performance value is (3.75), $(\mathrm{d}+\mathrm{r}=6.850)$. Zoumatang Village has the typical charm of a water town in the southern lower reaches of the Yangze River with beautiful natural scenery and where the ancient relics of Chinese civilization 
and a complete village pattern still survive. The vitality of cultural heritage and cultural relics is particularly apparent [56], which can satisfy tourists' different recreational motives such as leisure, entertainment, exploration, and knowledge seeking. However, although the satisfaction is relatively high, when it comes to higher psychological pleasure needs, the score drops slightly. Pleasure includes "tragic" aesthetics in addition to their usually understood meaning, and both elegant and popular pleasure [68]. From the above research results, we can see that, although the overall satisfaction score for the pleasure criterion is very high, it is still necessary to think about how the future spatial planning and design of a rural settlement can prove pleasurable by creating aesthetic (drama, tragedy) and both refined and popular pleasure to meet the tastes of tourists ranging from low-level sensory stimulation to high-level psychological needs. In addition, according to the causality diagram of the key criterion (Figure 3), it can be seen that "pleasure" is directly affected by "variation" (A6). Therefore, paying attention to the variation of visual and other clues in the tourism experience process, the comparison of changes in landscape environment, fineness, and complexity can help tourists to obtain maximum pleasure.

Naturality is a key factor in the aesthetic experience of Zoumatang Village visitors (ranking fifth in the overall ranking), and the satisfaction with naturality is 4.125 . In addition, naturalness $(\mathrm{d}-\mathrm{r}=0.940)$ affects most other criteria and is an important leading factor. Naturality affects pleasure to a great extent. It is very important to continue to maintain the advantages of this criterion for improving the tourists' overall satisfaction with their aesthetic experience. The satisfaction with Zoumatang Village's naturalness is high, which means that tourists are satisfied with the physical characteristics, sanitary conditions, maintenance, and structural integrity of the settlement as well as its wild and ecologically natural surroundings. Zoumatang Village was rated as one of the third batches of Chinese traditional villages in the seventh batch of famous Chinese historical and cultural villages. The basic pattern, environmental texture, and social and spatial structure are well preserved, and the total quantity of historical remains is relatively large. Wooden structures account for more than $60 \%$ of the total construction area of the ancient village. Among them, there are a large number of rich types of traditional buildings from the late Qing and early Ming Dynasties and exquisite wood carvings, inscriptions, poems, stone windows, and ancient bridges. The village has towering ancient trees, ponds, a dense water network, rich biological communities, and a relatively complete structure. The "Gongjin Monument" set up by the forefathers of Zoumatang Village warned descendants to pay attention to environmental protection, which led to it becoming today's Millennium Ecological Village [57]. However, naturalness is not only related to the area covered by green plants or the degree of wildness, but also the extent to which human intervention affects the display of naturalness. Therefore, some human cultural intervention should be carried out according to local conditions to prevent the original ecology from being destroyed whilst providing advanced living facilities and energy sources, e.g., sanitary equipment, stoves, wind energy, biogas, and solar energy.

"Recognizability" ranks second overall ( $\mathrm{d}-\mathrm{r}=-1.213)$, which shows that Zoumatang Village can better arouse tourists' appreciation by combining local and attractive images and clarifying the positioning, pattern, form, and content of the settlement itself. According to the analysis of the satisfaction questionnaire, tourists scored 4.5 points for the spatial pattern design of Zoumatang Village, and 3.8 points for the form of its tourism content, while other options related to recognition (such as the satisfaction value of the settlement tourism brand image, construction of cultural self-confidence, attraction, and personalization) were slightly lower, but each option was above the threshold of 3.5 points, so the advantages of this criterion remain.

\subsubsection{Key Factors but Low Satisfaction}

The results showed that interactivity, variety, associability, sociability, and stewardship are all key criteria, but their performance is not good, so they need to be improved. 
Interactivity mutually influences mysteriousness, pleasure, and associability, with a strong correlation. At the same time, interactivity is also influenced by disturbance $(d-r=1.131)$, naturalness $(d-r=0.940)$, scale $(d-r=0.751)$, genuineness $(d-r=0.616)$, coherence $(d-r=0.442)$, variety $(d-r=0.186)$, and tech-awareness $(d-r=0.315)$. Interactivity $(\mathrm{d}-\mathrm{r}=-0.475)$ influences pleasure $(\mathrm{d}-\mathrm{r}=-0.505)$, pleasure influences associability $(\mathrm{d}-\mathrm{r}=-0.623)$, sociability $(\mathrm{d}-\mathrm{r}=-1.160)$, and recognizability $(\mathrm{d}-\mathrm{r}=-1.213)$. Interactivity refers to people's interaction and participation in the environment. Nowadays, tourist attitudes have changed from passive acceptance to active pursuit and pay increasing attention to heartfelt emotional interaction. At present, Zoumatang Village has a unique water system advantage, but it fails to take advantage of it. The projects that tourists can enjoy are basically based on land, with a single perspective and low interactivity. In addition, the enthusiasm of local villagers to participate in environmental interaction and maintain the beauty of the settlement space landscape is not high.

Zoumatang Village is surrounded by several rivers. Donglingcao, Shaojiacao, Xieduji, Houwangcao, and Xujiacao are scattered among them. There are also more than ten small ponds of different sizes and shapes in the village. Efforts should be made to take advantage of the unique water system by building many quays and bridges to form water networks and a road network interchange corridor, thereby reviving the past prosperity of the ancient village. On this basis, it is necessary to protect and repair original old streets, judiciously add various facilities, combine the waterway experience with the land experience, and form an interactive, open space, cultural system linked to water sources. This will allow tourists to experience the water town characteristics, antiquity, and pastoral nature of the ancient village from different perspectives, immerse themselves in the unique ancient village environment, and engage in positive and multi-sensory interactions.

In a given community, the impact of people's familiarity with the environment and long-term interaction cannot be ignored. The resident can favor or hinder the future of tourism in a region with his/her actions [69]. "Villagers" should also become an important part of the aesthetic experience since they not only provide grass-roots services for tourists, but also need to participate in tourism development, give full play to the interactivity between villagers and the environment, and show the practical interactions of unique products, livelihoods [70], and farming culture to provide tourists with a deeply immersive and satisfying aesthetic experience.

Variety ranks fourth $(\mathrm{d}-\mathrm{r}=0.186)$ as a causal factor, but the performance rating (3.125) needs to be improved urgently. Variety reflects the organic integration of architectural and artistic elements and the vegetative terrain; also, the scale of the landscape elements and units is fine and full of perceptual, spatial, and temporal changes. The original agricultural landscape matrix of Zoumatang Village is relatively uniform in both scale and variety, which reduces the aesthetic experience. This finding is consistent with Arriaza's [71] proposal that the greater the homogeneity of our agricultural landscape, the reduction of crop diversity, the lower its perceived visual beauty, due mainly to the lack of colour contrast. It is necessary to improve the degree of mixed land use, adjust the areas devoted to various plants such as bluegrass, vegetables, and orchards, improve the utilization rate of agricultural land, and introduce some Pond Agriculture to form a fine-grained landscape. Zoumatang Village has a developed water system that is a visual resource with ecological, economic, and recreational value. When planning and designing new features, the type and variety of water bodies and the visual quality of the waterscape can be considered. Landscapes with water-related features (area, color, reflection, waves, sound, liveliness) as their main attributes can create a varied, perceptually rich, visual environment that is full of vitality and vigor. The preference for waterscapes reflects the findings of some previous studies. For example, waterscapes can link hearing and vision to create a combined audiovisual landscape design that has the potential to improve mental health and well-being [72]. While improving the variety of local and surrounding scenic locations, it is necessary to assess their suitability so as not to cause congestion, damage the quality of entertainment 
activities and traditional culture, or increase conflicts between different groups [73], all of which can be catastrophic for social, environmental, and ecological resources.

The criterion of "association" ranks fifth with naturalness, but the performance value is low, only three points, which is the key factor showing that the aesthetic experience of Zoumatang Village tourists needs to be improved urgently. Zoumatang Village is the foremost Jinshi village in China with an ancient farming culture and a naturally beautiful setting. Together, farming and culture can be united and utilized, along with poems, travel notes, and legends, to arouse tourists' interest and enrich and strengthen their interpretation and judgment of beauty whilst enhancing the village's aesthetic value by filling in missing details and connecting with all aspects of its aesthetic objects. At the same time, taking the characteristic farming culture as the main resource and the government as the leading actor, the villagers, enterprises, and social forces can cooperate in multiple ways to jointly develop tourism and improve tourists' perceptual interpretation of nature and humanity, which will help to enhance the tourists' satisfaction and pleasure with the aesthetic experience in Zoumatang Village. This conclusion echoes the association of literature, folk customs, painting, poetry, and other things to strengthen the aesthetic experience generated through sensory stimulation [14,44], enrich people's understanding of nature [42], and contribute to tourists' emotional expression [73].

Overall, stewardship is ranked eighth ( $\mathrm{d}-\mathrm{r}=-0.158$; performance value 3.375). Stewardship reflects that people take care of the landscape through active and careful management, implying the existence of a sense of order and care, which is helpful to people's perception of the "ideal" situation. Zoumatang Village has a considerable number of scenic locations and a good foundation for the protection of traditional villages, but there are social consciousness faults at the spiritual level and a lack of management systems at the material level: the management system of Zoumatang Village needs to be improved, the protection of public infrastructure is inadequate, the existing public toilets and garbage cans in the village are insufficient, and some of them have been damaged, so it is necessary to increase investment and daily protection. The water quality of the river is poor and disordered piles of garbage show that the villagers are unaware of the need for environmental protection and hygiene. The quality of protection for culturally significant buildings on both sides of the main roads and in the core protected areas in the village is good, but the general vernacular buildings at the village boundary and other traffic-free areas are derelict, dilapidated, or collapsed; the roads, lighting, water supply, and drainage facilities are aging; and the living environment is deteriorating, all of which detract from the overall environmental beauty of the ancient village. As the villagers have a poor educational background, their value recognition of material space as a cultural carrier is limited. The phenomenon of private construction, reconstruction, and the expansion of housing is more serious. The shape and material of modern small houses obliterate the original charm of ancient villages and destroy the integrity and unity of settlements. In addition, due to lack of management, many farmers build their own houses scattered at random, causing a certain degree of damage to farmland substrates. Therefore, under the guidance of policies, it is necessary to strengthen the quality of villagers' education, guide them to participate in the process of settlement construction and development, and to use inherited local traditional construction techniques to improve their awareness of protection and cohesion. It is a process of space construction, which stimulates departments at all levels to work together with the villagers to maintain the beauty of the settlement's spatial landscape, transmit positive energy to tourists, and further enhance tourists' satisfaction with their aesthetic experience. This conclusion is consistent with the active participation of the public in community construction work to make sure the local aesthetics are substantially implemented, help to enhance the villagers' community awareness and cohesion, and have a positive impact on the villagers' physical and mental health [74]. In the survey, it was found that the villagers in the settlement lack an understanding of professional knowledge and confidence in their own ability. In order to enhance the participation and interactivity of villagers, it is necessary to use appropriate communication methods, and 
provide different interactive platforms and information about different dimensions of landscape development in the region, so that they can realize their skills and strengthen their self-confidence. This finding is consistent with Luz's [75] proposal that the importance of landscape development for the local quality of life should be explicitly communicated, particularly in order to activate people with strong ties to a municipality. This conclusion also confirms the proposal of Höppner et al. [76], that communication strategies should focus on people's attachment to the local area, their perceived self-efficiency, confidence in the project (confidence in tangential outcomes of such a workshop), and interest in the development of their local landscape so as to improve people's motivation to participate in discussing events. Traditional settlements not only have value as precious cultural relics, but also carry the life of the villagers in the settlement, activating the settlement space to better continue the life value of the village, which is first based on the villagers' own cognition and willingness. Therefore, in terms of improving villagers' interactivity and participation, attention should be paid to communication methods, and villagers' knowledge and opinions on aesthetic reactions should be widely collected with understanding the actual needs of villagers in settlements as the main consideration.

In addition, efforts should be made to further improve the community management system and improve the construction of supporting facilities such as commercial and cultural services and medical care. Optimizing the landscape pattern of Zoumatang Village will help protect its residential culture and residential space landscape, including the neighborhood relationships of the original community; improve the cultural consciousness of the villagers; reserve the space for, possibly self-built, additional construction for the villagers at the technical level; ensure the sustainable natural development of the village; formulate medium- and long-term plans for rural development; recycle and integrate any idle spaces, landscapes, cultivated land and other types of spaces resulting from the population loss in the village; redistribute homesteads or convert them for other purposes; reserve resettlement space for long-term planning; repair the road network, pay attention to the ecological construction of transportation, promote green transportation and improve the transportation system; and, to encourage the use of green transportation, strengthen the construction of service facilities, such as greenways, rest seats, and commercial and repair services along the way.

Sociability ranks fifth overall (result factor $\mathrm{d}-\mathrm{r}=-1.160$; performance value 3.25). Sociability includes internal social interaction (promoting relationships with family or friends) and external social interaction (contacting all kinds of people and making new friends in strange places). Through social interaction, tourists can reach their best physical and mental state, give full play to their various talents and potentials, and realize their ideals and ambitions. Sociability is affected by interactivity, variation, association, and stewardship, as mentioned above. When the above factors are further improved, it will drive the sociability of visitors.

\subsubsection{Factors with Average Importance and Low Satisfaction}

Tech-awareness, coherence, and distance factors all have general importance and low satisfaction from tourists, with the criteria of low satisfaction being given priority. Tourists satisfaction with Zoumatang Village's tech-awareness $(\mathrm{d}-\mathrm{r}=0,315)$ is low, only 2.5 points, which needs improvement. Under the test of the pandemic, the online development process of China's cultural tourism industry is moving to a new level. According to the Online Tourism Assets Index (TPI) Report in the Third Quarter of 2020 released by Mafengwo Tourism, the increasingly diversified rural tourism experience in China has attracted an increasing number of young tourists who are accelerating the development of "rural tourism" online. Therefore, in terms of tech-awareness, besides paying attention to the sharing of tourism information and audio-visual and video experiences, it is also necessary to adapt to the new requirements of the "new normal" of epidemic prevention and control to ensure a civilized tourism experience starting with making bookings and reservations; meeting the new needs of tourists, including the introduction of new routes 
and products; and displaying new images and ways of experiencing civilized rural tourism. When the aesthetic experience and the overall satisfaction of tourists in Zoumatang Village are improved, these three items will naturally attract tourists. With the availability of abundant settlement resources, we can start to improve the factors of coherence, distance, and tech-awareness.

\subsubsection{Factors with Average Importance and High Satisfaction}

The average importance of, and high satisfaction with, mysteriousness $(\mathrm{d}-\mathrm{r}=-0.255)$, genuineness $(\mathrm{d}-\mathrm{r}=0.616)$, distinctiveness $(\mathrm{d}-\mathrm{r}=0.062)$, education $(\mathrm{d}-\mathrm{r}=-0.054)$, and scale $(\mathrm{d}-\mathrm{r}=0.751)$ is noted. Among them, mysteriousness and education are influenced by most criteria, and the satisfaction scores of both criteria are 3.75 points. This shows that tourists agree with the brand image and cultural orientation of Zoumatang Village. Tourists generally feel that in the process of traveling, different recreational motives such as leisure, sightseeing, entertainment, exploration, and seeking knowledge are satisfied. Therefore, there is no need to pay too much attention to the two principles of mysteriousness and education at present.

The criteria of genuineness, distinctiveness, and scale are causal factors, and their satisfaction is high, so it is necessary to carefully maintain the advantages of the three criteria. However, scale reflects the scale of the environment and the openness of the field of vision, allowing tourists to fully perceive the openness of the space, the density of landscape elements and the number of obstacles. Scale $(d-r=0.751)$ is affected by naturalness $(\mathrm{d}-\mathrm{r}=0.940)$ and distance $(\mathrm{d}-\mathrm{r}=1.131)$. This study suggests that when planning the settlement space as a whole, special consideration should be given to the different situations during peak and normal periods. This conclusion supports the view that population size, population density, richness of visual cues in the environment, color type and intensity, spatial openness, and congestion will all affect "scale" [9]. Scale's satisfaction score is 3.75, slightly higher than the threshold of 3.5. The advantages of this criterion should be carefully maintained remembering that there is still room for improvement and promotion.

\subsection{Research Implications}

China's countryside is rich in cultural heritage. It is a tourist place combining leisure and education and an important engine for rural development and revitalization. Rural tourism has become an important force in China's domestic tourism and an effective means of developing the rural economy. With the rapid increase of tourists and the improvements made to meet their various demands, rural tourism is also facing the challenge of sustainable development. At present, the over-exploitation and over-commercialization of rural tourism in China had a negative impact on the aesthetic experience of tourists. It is worth considering how to balance the authenticity and theatricality of aesthetic activities in rural tourism, reconcile the transmutation and alienation of tourism aesthetics, and construct an ideal rural tourism landscape. In addition, COVID-19 has contributed the rise of local tourism worldwide, especially rural tourism [77,78]. Most papers on rural tourism are studied from the perspective of tourists, tourism management, and rural tourism development. For example, Vaishar, Antonín et al. [79] note that the COVID-19 epidemic has created opportunities for the development of rural tourism. Rural tourism requires investment in infrastructure, marketing, and regional cooperation. Xu, Keshuai et al. [80] based on leadership theories and the literature on community leadership and tourism development, this study developed a framework for community leadership in rural tourism development and used it to examine two ancient Chinese villages. From the perspective of rural tourists' aesthetic experience, this study puts forward an important framework for factors influencing their satisfaction with their aesthetic experience to fill gaps in the research field. To provide a new perspective for achieving the goal of sustainable rural tourism development and constructing an ideal rural tourism landscape and contribute to the development planning and integrated marketing of rural tourism. The study of the aesthetic experience of tourists is conducive to the realisation of sustainable alternative 
forms of rural tourism, the construction of desirable destinations and the defence against negative events such as COVID-19. The research method proposed in this study is different from the general research methods related to experience, such as the aesthetic experience usability index [45] and the models for measuring tourism experience [30] proposed by other scholars, since it focuses more on tourists' aesthetic experience. However, combined with the latest definition of user experience and the content of SEMs, the evaluation criteria of tourists' aesthetic experience satisfaction proposed in this study are not identical to those proposed by other scholars, and cover five dimensions: sensory experience, emotional experience, thinking experience, action experience, and related experience. This study deepens the understanding of the aesthetic experience of our tourism researchers, offers recommendations for policymakers and tourism stakeholders not only in Zoumatang Village in Ningbo, but also around the world to facilitate the development of rural tourism. The criterion framework proposed in this study can be used in the process of aesthetic perception and the aesthetic experience design of spatial environments, questionnaire making, creating an evaluation index, and decision optimization, which is innovative and of research value. This study is an empirical study, and its research results can provide decision-making options for Zoumatang Village's spatial planning and provide research methods and ideas for rural environmental spatial planning, rural tourism development, and integrated marketing, which have practical application value. In addition, this study used D-ANP to find the strong or weak influence relationships between factors, so that decision-makers can examine and analyze each factor in a global and interactive way.

Among the 16 criteria proposed in this study, pleasure is the core criterion with the highest importance, whilst tech-awareness is the criterion with the least importance. Both of them can be changed according to specific tourism themes, such as packages for parentchild leisure experiences, farming and reading experiences, and research experience. The coherence criterion also takes into account the aesthetic image, aesthetic accomplishment, and the artistic sensibilities of service personnel. It is not only applicable to aesthetic experience in the field of space design, but also applicable to aesthetic experience in the field of product design and industrial design. Scale is a relatively common criterion suitable for various types of aesthetic experience. Education, sociability, and recognition are the factors that distinguish the aesthetic experience of rural tourists from other experiences, and are criteria rarely mentioned in the existing literature on the aesthetic experience of rural tourism. The three are closely related and the new criterion of recognizability proposed in this paper, which is very important because it is easier to gain a competitive advantage in a market with many similar products by creating an attractive, personalized, and differentiated brand image for settlement tourism, constructing cultural self-confidence, and arousing tourists' remembrance and recognition. In addition, the recognizability criterion extracted from SEM theory conforms to the definition of user experience in recent years, and good recognition is helpful for enhancing tourists' willingness to revisit.

\section{Conclusions}

The proposal and implementation of a series of policies, such as new countryside, beautiful countryside, characteristic towns, and rural revitalization, have ushered in new opportunities for rural regeneration and spawned a large amount of rural tourism. The literature review shows that presently, academics pay more attention to the hierarchy, connotation and role of aesthetic experience, but qualitative research is the main focus, while a small amount of empirical research focuses on the sensory aspect of aesthetic experience. For example, Kirillova et al. [9] drawing on the literature in environmental psychology, attempted to reveal dimensions of tourist aesthetic judgment. Through semi-structured interviews, the analysis yielded 21 aesthetic dimensions, which were grouped into nine themes. Subiza-Pérez et al. [31] developed the PEAQS to measure the aesthetic quality of a tourist attraction, but the scale only focuses on the aesthetics of the natural physical environment and does not address the deeper emotional and spiritual aspects of aesthetics. Breiby et al. [32] construct an aesthetic experience scale with five dimensions from 
sensory aspects: "harmony", "variation/contrast", "scene/viewing", "genuineness", and "art/architecture". In the current context of integrated development of cultural tourism, aesthetic experience can explain to a certain extent the phenomenon of low revisit rate and loyalty, low interaction and poor sense of identity. Therefore, it is necessary to conduct a quantitative empirical study from multiple perspectives. Up to now, no framework for the evaluation of Chinese rural tourists' satisfaction with their aesthetic experience has been established. According to Schmitt's SEMs, the evaluation criteria of tourists' aesthetic experience satisfaction in Zoumatang Village were divided into five dimensions: sensory experience, emotional experience, thinking experience, action experience, and related experience. After discussion of the literature and two rounds of the Delphi method, 16 relatively important criteria were obtained, which paved the way for subsequent research. Using DEMATEL-based ANP, the importance ranking and causality diagrams for the 16 criteria were obtained. The order of importance from high to low is pleasure (B2), juxtaposed interactivity (D1) and recognizability (E2), variation (A6), juxtaposed naturalness (A3) and association (C2), sociability (E1), stewardship (A7), mysteriousness (B1), genuineness (A2), distinctiveness (B3), education (C1), scale (A1), juxtaposed distance (A4), coherence (A5), and Tech-awareness (D2). Based on the first half of the ranking, the selected key criteria include: pleasure, interactivity, recognizability, variation, naturalness, associability, sociability, and stewardship. According to the DEMATEL-based ANP method, the key factors affecting tourists' satisfaction with their aesthetic experience in Zoumatang Village can be effectively evaluated. The IPA chart of tourists' aesthetic experience satisfaction in Zoumatang Village shows that pleasure, naturalness, and recognizability are the key and high-satisfaction criteria, which can continue to maintain their advantages, but there is still room for improvement. Interactivity, variety, associability, sociability, and stewardship are the key criteria with low satisfaction. It is urgent to further improve tourists' satisfaction with their aesthetic experience based on these criteria. Coherence, tech-awareness, and distance are generally important factors but with low satisfaction, which can be improved by increasing settlement resources. Scale, genuineness, mysteriousness, distinctiveness, and education are factors of average importance and high satisfaction, which need to be maintained although needing rather less attention.

Based on academic theory and a real-case situation, this paper provided a framework for the evaluation of tourists' satisfaction with their aesthetic experience in Zoumatang Village, analyzed the specific conditions of each criterion in combination with tourists' satisfaction, and gave reference suggestions for improving the aesthetic experience of tourists in rural settlements, in order to further enhance tourists' willingness to revisit, thus, promoting tourists' physical and mental health. This study provides a model of an evaluation framework, and this initial contribution is available to other authors in the same field for further testing, verification, and improvement. The implications of tourists' aesthetic experience design management proposed in this paper may be limited to Chinese rural settlements rather than international rural settlements. Therefore, in the follow-up research, efforts can be made to administer an international version of the satisfaction questionnaire of rural settlement tourists' aesthetic experience design, so as to improve the international applicability of this study. In addition, this study can provide reference research ideas for similar rural settlements, but it may not be completely applicable to the promotion of tourists' aesthetic experience design in other types of settlements.

Author Contributions: Conceptualization, W.Z., L.-Y.C. and R.-J.C.; Formal analysis, W.Z., L.-Y.C. and R.-J.C.; Investigation, W.Z.; Methodology, W.Z., L.-Y.C. and R.-J.C.; Supervision, L.-Y.C. and R.-J.C.; Writing—original draft, W.Z.; Writing—review \& editing, L.-Y.C. and R.-J.C. All authors have read and agreed to the published version of the manuscript.

Funding: This research was funded by [The project of philosophy and social science planning in Zhejiang Province: The Research on Countryside Space Reconstruction Path under The Intervention of Art in Zhejiang] grant number [21NDJC176YB].

Institutional Review Board Statement: Not applicable. 
Informed Consent Statement: Not applicable.

Data Availability Statement: Not applicable.

Conflicts of Interest: The authors declare no conflict of interest.

\section{References}

1. Wang, F.; Xie, Z.; Wu, B. A study on the influence of spatial scale of landscape on tourists' satisfaction and the mediating role of emotional experience. Hum. Geogr. 2018, 33, 142-151.

2. Hung, Y.F. Study on the Evaluation Index System of Public Cultural Space Satisfaction of Traditional Villages in Cold Regions Based on Tourists' Satisfaction. Master's Thesis, Harbin Institute of Technology, Harbin, China, 2018.

3. Waitt, G. Selling paradise and adventure: Representations of landscape in the tourist advertising. Aust. Geogr. Stud. 1997, 35, 47-60. [CrossRef]

4. Walmsley, D.J. Rural tourism: A case of lifestyle-led opportunities. Aust. Geogr. 2003, 34, 61-72. [CrossRef]

5. Cha, S.; McCleary, K.W.; Uysal, M. Travel Motivations of Japanese Overseas Travelers: A Factor-Cluster Segmentation Approach. J. Travel Res. 1995, 34, 33-39. [CrossRef]

6. Wu, B.H.; Xu, B.; Qiu, F.D. Study on the System of China's Domestic Tourist Market; East China Normal University Press: Shanghai, China, 1999.

7. Huang, J. Soil Complex, Family Complex and Agritourism Development. Ideol. Front. Yunnan Univ. J. Soc. Sci. 2003, 5, 24-26.

8. Lue, C.-C.; Crompton, J.L.; Fesenmaier, D.R. Conceptualization of multi-destination pleasure trips. Ann. Tour. Res. 1993, 20, 289-301. [CrossRef]

9. Kirillova, K.; Fu, X.; Lehto, X.; Cai, L. What makes a destination beautiful? Dimensions of tourist aesthetic judgment. Tour. Manag. 2014, 42, 282-293. [CrossRef]

10. Oh, H.; Fiore, A.M.; Jeoung, M. Measuring experience economy concepts: Tourism applications. J. Travel Res. 2007, 46, 119-132. [CrossRef]

11. Hosany, S.; Witham, M. Dimensions of cruisers' experiences, satisfaction, and intention to recommend. J. Travel Res. 2010, 49, 351-364. [CrossRef]

12. Chu, H.; Wang, J. Literature Review of Tourism Aesthetics Research. Tour. Overv. Ind. Version 2011, 4, 69-71.

13. Yang, D.; Luo, T.; Lin, T.; Qiu, Q.; Luo, Y. Combining aesthetic with ecological values for landscape sustainability. PLoS ONE 2014, 9.7, e102437. [CrossRef]

14. Zhang, Q.; Xu, H. Understanding aesthetic experiences in nature-based tourism: The important role of tourists' literary associations. J. Destin. Mark. Manag. 2020, 16, 100429. [CrossRef]

15. Breiby, M.A.; Slåtten, T. The effects of aesthetic experiential qualities on Tourists-positive emotions and loyalty: A case of a nature-based context in Nor. Qual. Assur. Hosp. Tour. 2015, 16, 323-346. [CrossRef]

16. Hall, N.A. Aesthetic Perception, Nature and Experience; The University of Edinburgh: Edinburgh, UK, 2014.

17. Wang, Y.; Xia, Z.; Chen, W. Aesthetic Values in Sustainable Tourism Development: A Case Study in Zhangjiajie National Park of Wuling Yuan, China. J. China Tour. Res. 2008, 4, 205-218. [CrossRef]

18. Bourassa, S.C. Toward a theory of landscape aesthetics. Landsc. Urban Plan. 1988, 15, 241-252. [CrossRef]

19. Babich, B. (Ed.) Nietzsche's Aesthetic Science and Hume's Standard of Taste. In Reading David Hume's 'of the Standard of Taste'; De Gruyter: Boston, MA, USA; Berlin, Germany, 2019.

20. Ginsborg, H. Kant's Aesthetics and Teleology; Metaphysics Research Lab, Stanford University: Stanford, CA, USA, 2005.

21. Daniel, T.C. Whither scenic beauty? Visual landscape quality assessment in the 21st century. Landsc. Urban Plan. 2001, 54, 267-281. [CrossRef]

22. Charters, S. Aesthetic products and aesthetic consumption: A. review. Consum. Mark. Cult. 2006, 9, 235-255. [CrossRef]

23. Wu, H.L. Urban-Rural Dual Structure of Tourism Aesthetics. Thinking 2018, 44, 148.

24. Zhang, C.; Zhao, B.F. On the Value Orientation of Life Aesthetics and Its Practical Significance. J. Soc. Theory Guide. 2018, 5, 101-107.

25. Yang, Z. Ministry of Culture and Tourism: Rural Tourism Numbers Recovered by more than $90 \%$ in the Same Period Last Year. Xinhua Network. 13 September 2020. Available online: http:/ /guoqing.china.com.cn/2020-09/13/content_76697461.htm (accessed on 13 February 2021).

26. Lv, Y. Rural Tourism on Fire "Go to the Country!" Becoming the First Choice for a Trip, People's Daily Overseas Edition. 16 September 2020. Available online: http:/ /guoqing.china.com.cn/2020-09/16/content_76707305.htm (accessed on 13 February 2021).

27. Hu, Y.C.; Chiu, Y.J.; Hsu, C.S.; Chang, Y.Y. Identifying key factors for introducing GPS-based fleet management systems to the logistics industry. Math. Probl. Eng. 2015, 2015. [CrossRef]

28. Chi, C.G.-Q.; Qu, H. Examining the structural relationships of destination image, tourist satisfaction and destination loyalty: An integrated approach. Tour. Manag. 2008, 29, 624-636. [CrossRef]

29. Kozak, M. Repeaters' behavior at two distinct destinations. Ann. Tour. Res. 2001, 28, 784-807. [CrossRef]

30. Wang, W.; Chen, J.S.; Fan, L.; Lu, J. Tourist experience and wetland parks: A case of Zhejiang, China. Ann. Tour. Res. 2012, 39, 1763-1778. [CrossRef] 
31. Subiza-Pérez, M.; Hauru, K.; Korpela, K.; Haapala, A.; Lehvävirta, S. Perceived Environmental Aesthetic Qualities Scale (PEAQS)-A self-report tool for the evaluation of green-blue spaces. Urban For. Urban Green. 2019, 43, 126383. [CrossRef]

32. Breiby, M.A. Exploring aesthetic dimensions in a nature-based tourism context. J. Vacat. Mark. 2014, 20, 163-173. [CrossRef]

33. Funch, B.S.; Krøyer, L.L.; Roald, T.; Wildt, E. Long-term effect of aesthetic education on visual awareness. J. Aesthetic Educ. 2012, 46, 96-108. [CrossRef]

34. Pine, B.J.; Gilmore, J. Welcome to the experience economy: Harvard Business Review. July August 1998, 76.4, 97-105.

35. Anton, C.; Camarero, C.; Garrido, M.-J. Exploring the experience value of museum visitors as a co-creation process. Curr. Issues Tour. 2018, 21, 1406-1425. [CrossRef]

36. Vickers, N.J. Animal communication: When i'm calling you, will you answer too? Curr. Biol. 2017, 27, R713-R715. [CrossRef]

37. Li, W. On the Development Orientation of the Rural Tourism in Our Country. Tour. Res. 2007, 18, 1-6.

38. Chen, T.K.; Miao, S.H. The Quantitative Research on Domestic Tourism Motivations of Urban Inhabitants-The Case Study of Kaifeng, Henan Province. Tour. Trib. 2006, 21, 22-28.

39. Gobster, P.H.; Nassauer, J.I.; Daniel, T.C.; Fry, G. The shared landscape: What does aesthetics have to do with ecology? Landsc. Ecol. 2007, 22, 959-972. [CrossRef]

40. Baloglu, S.; McCleary, K.W. A model of destination image formation. Ann. Tour. Res. 1999, 26, 868-897. [CrossRef]

41. Yu, X.; Xu, H. Ancient poetry in contemporary Chinese tourism. Tour. Manag. 2016, 54, 393-403. [CrossRef]

42. Xu, H.; Cui, Q.; Ballantyne, R.; Packer, J. Effective environmental interpretation at Chinese natural attractions: The need for an aesthetic approach. J. Sustain. Tour. 2013, 21, 117-133. [CrossRef]

43. Heyd, T. Aesthetic Appreciation and The Many Stories About Nature. Br. J. Aesthet. 2001, 41, 125-137. [CrossRef]

44. Brady, E. Imagination and the Aesthetic Appreciation of Nature. J. Aesthet. Art Crit. 1998, 56, 139. [CrossRef]

45. Leder, H.; Belke, B.; Oeberst, A.; Augustin, D. A model of aesthetic appreciation and aesthetic judgments. Br. J. Psychol. 2004, 95, 489-508. [CrossRef]

46. Kaplan, S. Aesthetics, affect, and cognition: Environmental preference from an evolutionary perspective. Environ. Behav. 1987, 19, 3-32. [CrossRef]

47. Kaplan, R.; Kaplan, S.; Brown, T. Environmental preference: A comparison of four domains of predictors. Environ. Behav. 1989, 21, 509-530. [CrossRef]

48. Mooser, A.; Anfuso, G.; Gómez-Pujol, L.; Rizzo, A.; Williams, A.; Aucelli, P. Coastal Scenic Beauty and Sensitivity at the Balearic Islands, Spain: Implication of Natural and Human Factors. Land 2021, 10, 456. [CrossRef]

49. Herzorg, T.R.; Herbert, E.J.; Kaplan, R.; Crooks, C.L. Cultural and developmental comparison of landscape perceptions and preferences. Environ. Behav. 2000, 32, 323-346. [CrossRef]

50. Rogge, E.; Nevens, F.; Gulinck, H. Perception of rural landscapes in Flanders: Looking beyond aesthetics. Landsc. Urban Plan. 2007, 82, 159-174. [CrossRef]

51. Hosseini, F.; Sajadzadeh, H.; Aram, F.; Mosavi, A. The Impact of Local Green Spaces of Historically and Culturally Valuable Residential Areas on Place Attachment. Land 2021, 10, 351. [CrossRef]

52. Fyhri, A.; Jacobsen, J.K.S.; Tømmervik, H. Tourists' landscape perceptions and preferences in a Scandinavian coastal region. Landsc. Urban Plan. 2009, 91, 202-211. [CrossRef]

53. Schmitt, B. Experiential Marketing. J. Mark. Manag. 1999, 15, 53-67. [CrossRef]

54. Tasci, A.D.; Milman, A. Exploring experiential consumption dimensions in the theme park context. Curr. Issues Tour. 2019, 22, 853-876. [CrossRef]

55. Musa, G.; Mohammad, I.; Thirumoorthi, T.; Moghavvemi, S.; Kasim, A. Exploring visitors' experience using strategic experiential modules (SEMs): The case of Zoo Negara, Kuala Lumpur. Int. J. Tour. Cities 2015, 1, 234-253. [CrossRef]

56. Xu, C.M. Famous Historical and Cultural Towns and Villages in Ningbo: Zoumatang; Ningbo Publishing: Zhejiang, China, 2008.

57. Xu, B.L.; Wang, Y.; Huang, F.Y. The First Jinshi Village in China: Zoumatang; Sichuan Peoples Publishing House: Sichuan, China, 2008.

58. Saaty, T.L. Decision Making with Dependence and Feedback: The Analytic Network Process; RWS Publications: Pittsburgh, KS, USA, 1996.

59. Teng, J.Y. Multiple Criterion Decision Making: Methods and Applications; Tingmao Books Press: Taipei, Taiwan, 2012.

60. Tzeng, G.-H.; Chiang, C.; Li, C. Evaluating intertwined effects in e-learning programs: A novel hybrid MCDM model based on factor analysis and DEMATEL. Expert Syst. Appl. 2007, 32, 1028-1044. [CrossRef]

61. Mirghaed, F.A.; Mohammadzadeh, M.; Salmanmahiny, A.; Mirkarimi, S.H. Assessing the interactions between landscape aesthetic quality and spatial indices in Gharasoo watershed, North of Iran. Int. J. Environ. Sci. Technol. 2020, 17, 231-242. [CrossRef]

62. Horng, J.S.; Liu, C.H.; Chou, S.F.; Tsai, C.Y. Creativity as a critical criterion for future restaurant space design: Developing a novel model with DEMATEL application. Int. J. Hosp. Manag. 2013, 33, 96-105. [CrossRef]

63. Tzeng, G.-H.; Huang, J.-J. Multiple Attribute Decision Making: Methods and Applications; CRC Press: Boca Raton, FL, USA, 2011.

64. Lee, Y.H.; Cheng, K.L. Incorporating Fuzzy Theory, DANP, and TOPSIS to Analyze Taiwan's Ecotourism Scenic Destinations Selectin. Yu Da Acad. J. 2013, 35, 31-56.

65. Qu, G.B.; Zhao, T.Y.; Zhu, B.W.; Tzeng, G.H.; Huang, S.L. Use of a modified DANP-mV model to improve quality of life in rural residents: The empirical case of Xingshisi village, China. Int. J. Environ. Res. Public Health 2019, 16, 153. [CrossRef] 
66. Murry, J.W., Jr.; Hammons, J.O. Delphi: A versatile methodology for conducting qualitative research. Rev. High. Educ. 1995, 18, 423-436. [CrossRef]

67. Cheng, Q.; Guo, J.; Ling, S. Fuzzy importance-performance analysis of visitor satisfaction for theme park: The case of Fantawild Adventure in Taiwan, China. Curr. Issues Tour. 2016, 19, 895-912. [CrossRef]

68. Zhang, G.J.; Wu, J.F. Re-thinking of Tourism Pleasure. J. Sichuan Norm. Univ. Soc. Sci. Ed. 2016, 43, 50-56.

69. Plaza-Mejía, M.; Porras-Bueno, N.; Flores-Ruiz, D. The Jungle of Support: What Do We Really Mean When We Say “Residents” Support"? Sustainability 2020, 12, 7795. [CrossRef]

70. Li, X.; Xie, C.; Morrison, A.M.; Nguyen, T.H.H. Experiences, Motivations, Perceptions, and Attitudes Regarding Ethnic Minority Village Tourism. Sustainability 2021, 13, 2364.

71. Arriaza, M.; Cañas-Ortega, J.; Cañas-Madueño, J.; Ruiz-Aviles, P. Assessing the visual quality of rural landscapes. Landsc. Urban Plan. 2004, 69, 115-125. [CrossRef]

72. Zhao, J.; Xu, W.; Ye, L. Effects of auditory-visual combinations on perceived restorative potential of urban green space. Appl. Acoust. 2018, 141, 169-177. [CrossRef]

73. Scolozzi, R.; Schirpke, U.; Detassis, C.; Abdullah, S.; Gretter, A. Mapping alpine landscape values and related threats as perceived by tourists. Landsc. Res. 2015, 40.4, 451-465. [CrossRef]

74. Mak, W.W.S.; Cheung, R.Y.M.; Law, L.S.-C. Sense of Community in Hong Kong: Relations with Community-Level Characteristics and Residents' Well-Being. Am. J. Community Psychol. 2009, 44, 80-92. [CrossRef] [PubMed]

75. Luz, F. Participatory landscape ecology_A basis for acceptance and implementation. Landsc. Urban Plan. 2000, 50, 157-166. [CrossRef]

76. Höppner, C.; Frick, J.; Buchecker, M. What Drives People's Willingness to Discuss Local Landscape Development? Landsc. Res. 2008, 33, 605-622. [CrossRef]

77. Lee, H.Y.; Leung, K.Y.K. Island ferry travel during COVID-19: Charting the recovery of local tourism in Hong Kong. Curr. Issues Tour. 2021, 1-18.

78. Marques, C.P.; Guedes, A.; Bento, R. Rural tourism recovery between two COVID-19 waves: The case of Portugal. Curr. Issues Tour. 2021, 1-7. [CrossRef]

79. Vaishar, A.; Št'astná, M. Impact of the COVID-19 pandemic on rural tourism in Czechia Preliminary considerations. Curr. Issues Tour. 2020, 1-5. [CrossRef]

80. Xu, K.; Zhang, J.; Tian, F. Community leadership in rural tourism development: A tale of two ancient chinese villages. Sustainability 2017, 9, 2344. [CrossRef] 